\title{
GCU
}

Glasgow Caledonian

University

University for the Common Good

\section{Using the root spread information of pioneer plants to quantify their mitigation potential against shallow landslides and erosion in temperate humid climates}

Gonzalez-Ollauri, Alejandro; Mickovski, Slobodan B.

Published in:

Ecological Engineering

DOI:

10.1016/j.ecoleng.2016.06.028

Publication date:

2016

Document Version

Author accepted manuscript

Link to publication in ResearchOnline

Citation for published version (Harvard):

Gonzalez-Ollauri, A \& Mickovski, SB 2016, 'Using the root spread information of pioneer plants to quantify their mitigation potential against shallow landslides and erosion in temperate humid climates', Ecological Engineering, vol. 95, pp. 302-315. https://doi.org/10.1016/j.ecoleng.2016.06.028

\section{General rights}

Copyright and moral rights for the publications made accessible in the public portal are retained by the authors and/or other copyright owners and it is a condition of accessing publications that users recognise and abide by the legal requirements associated with these rights.

Take down policy

If you believe that this document breaches copyright please view our takedown policy at https://edshare.gcu.ac.uk/id/eprint/5179 for details of how to contact us. 
1 Using the root spread information of pioneer plants to quantify their mitigation

2 potential against shallow landslides and erosion in temperate humid climates

Alejandro Gonzalez-Ollauri ${ }^{1,2}$ and Slobodan B. Mickovski ${ }^{1}$ 
51 Abstract

53 The aim of this paper was to quantify the mitigation potential of pioneer herbs against

54 shallow landslides and erosion in temperate humid climates and to identify key plant

55 information to aid species selection for slope stabilisation. The objectives ranged from

56 the study of the climate, soil and root spread of three native perennial herbs growing

57 on a landslide-prone slope in Northeast Scotland to the verification of an upgraded

58 spatially distributed eco-hydrological model in order to test whether root spread

59 information can be provided cost-effectively in temperate humid climates. The

60 retrieved information on root spread was then used to evaluate the slope stabilisation

61 potential of the pioneer herbs in the topmost soil horizons using a limit equilibrium

62 method.

63 The results indicated that pioneer herbs, although presenting climate-influenced

64 shallow root systems, could noticeably contribute to reducing soil mass loss and

65 landslides. This was largely determined by the plant biomass and allometry, the latter

66 being a potential readily measurable proxy for species selection in slope stabilisation

67 that will need further investigation. Additionally, our observations supported the

68 model predictions remarkably well when site-specific inputs were employed, showing

69 that the proposed model is a suitable and cost-effective tool to provide spatial root

70 spread information for eco-engineering purposes in temperate humid climates.

71

72 Key words: herb, root spread, temperate humid climate, allometry, distributed model, 73 shallow landslide. 
1. Introduction

Landslides and erosion are a global hazard that lead to dramatic loss of human life, property and soil every year with an occurrence that will likely increase due to the effects of climate and land use change (van Beek et al., 2008; IPCC, 2014) if action is not taken.

The use of plants against shallow landslides and erosion has been shown to be an effective eco-engineering measure (Stokes et al., 2014) mainly provided by the soilroot mechanical reinforcement (Norris et al., 2008). A root-permeated soil makes up a composite material that has enhanced strength (Waldron, 1977), providing a similar effect to the soil like that of steel rods to reinforced concrete (Mickovski et al., 2009). However, to quantify the extent of soil-root reinforcement, information on the root spread in the soil is needed to evaluate the slope stabilisation potential of the plant in the topmost soil horizons. Despite the relatively recent efforts to quantify root spread at a global scale (e.g.

95 Schenk and Jackson, 2002; Schenk and Jackson, 2005), it still remains unknown for the vast majority of the wild plant species. Indeed, information related to pioneer

97 herbs is severely scarce, as far more attention has been traditionally paid to woody 98 plant species (Stokes et al., 2008) and crops (Böhm, 1979). Pioneer herbs may present 99 a great eco-engineering potential as they are fast-growing, easily spreadable and set 100 the basis for further ecological succession (Odum and Barrett, 1971). However, herb’s 101 root systems are expected to be limited to the topmost soil horizons, being more likely 102 effective against rill or gully erosion (e.g. van Beek et al., 2008). Hence, the use of 
103 herbs in eco-engineering slope stabilisation actions needs to be combined with other 104 remediation techniques (e.g. Tardio and Mickovski, 2016).

105 The root distribution in the soil may be complex and, obtaining related information is 106 expensive and time-consuming. Thus, the development of numerical root distribution 107 models has been the scope of research in the past few decades (e.g. Wu et al., 2005) 108 and based on this research, for most practical eco-engineering applications, a root 109 profile can be portrayed as a simple asymptotic mathematical function (Jackson et al., 110 1996). Additionally, it has been observed that root spread is chiefly influenced by 111 water availability in the soil (i.e. 'hydrotropism'; Darwin, 1880; Tsutsumi, 2003). 112 This concept permits to link the root development to climate and soil properties 113 (Schenk and Jackson, 2002) and, therefore, to the soil's water balance. In this sense, 114 Laio et al. (2006) developed an analytical eco-hydrological model able to predict 115 realistically the rooting depth at the plant community level for water-limited 116 ecosystems (i.e. arid or dry environments) from readily available soil and climatic 117 predictors. These predictors can be easily parameterised from the soil 118 physicochemical properties (i.e. porosity, texture and organic matter content) and 119 from temperature and rainfall information collected by many weather stations. 120 However, the root spread has rarely been assessed using in situ soil and climate121 derived information as data from distant meteorological stations and sampling 122 locations are normally interpolated for a given study site (e.g. Preti et al., 2010; Tron 123 et al., 2014). Laiós et al. model was further extended by Preti et al. (2010) to provide 124 plant species-specific root profile information by the consideration of a universal 125 property to all living organisms, the allometry (West et al., 1997). Plants allocate their 126 biomass above and below the ground, and the proportion in which this is distributed 127 can be assessed by the plant's allometric relationship (Cheng and Niklas, 2007) 
depicted by a simple power-law relationship (West et al., 1997). This relationship permits to cost-effectively infer the root biomass from measurements of the aboveground biomass and also potentially determine plant parameters related to soil reinforcement purposes (e.g. Hwang et al., 2015). To the best of our knowledge, the

132 identification of plant indicators able to enhance the effectiveness of plant selection 133 against shallow landslides has been rarely explored (e.g. Cornelini et al., 2008). 134 Additionally, the existing models (Laio et al., 2006; Preti et al., 2010) are, essentially, 135 one-dimensional and cannot be readily applied to temperate humid climates (Tron et 136 al., 2014), which cover a big surface of the Earth (Köppen, 1884).

137 Climate, soil, and plant cover are spatially highly heterogeneous, which stresses the 138 need of adopting spatial approaches to predict root system features under different 139 environmental and landscape scenarios. However, spatially distributed root spread 140 models are lacking in the literature (e.g. O’Brien et al., 2007; Coelho et al., 2003), 141 although these types of models are very popular in hydrology and catchment science 142 (Neitsch et al., 2011; Doppler et al., 2014). The development of distributed root 143 spread models may be very helpful to assess the spatial effect of vegetation against 144 shallow landslides and erosion or to enhance the predictive capacity of other spatial 145 models aiming to quantify plant-derived processes (e.g. water fluxes, nutrient cycles 146 or sediment dynamics at the catchment scale; SWAT; Neitsch et al., 2011). However, 147 the performance of a given distributed model will rely on the quality of the spatial 148 information used as an input. In this sense, the implementation of machine learning 149 techniques, such as the random forest algorithm (RF; Breiman, 2001), for predicting 150 spatially heterogeneous soil variables that drive root spread in the soil (e.g. soil water 151 availability) may have great potential for providing spatial soil information cost152 effectively (Malone, 2013). RF was conceived to produce accurate predictions that do 
153 not overfit the data (Breiman, 2001), it is more powerful than classical spatial 154 interpolation methods (e.g. regression tree, universal kriging, cubist; Liess et al., 155 2012) and more interpretable than other machine learning techniques, such as neural 156 networks (Prasad et al., 2006). The use of these techniques in environmental studies, 157 although growing, is still poor.

158 The aim of this paper is to quantify the potential of pioneer herbs against shallow 159 landslides and erosion in temperate humid climates and identify key plant information 160 to aid species selection for slope stabilisation. To do so, we follow a step by step 161 journey from the study of the climate, soil and the root spread of three native 162 perennial herbs growing on a landslide-prone slope in Northeast Scotland, to the 163 verification of our revised spatially distributed eco-hydrological model; testing 164 whether root spread information can be provided cost-effectively in temperate humid 165 climates. The retrieved information on root spread is then used to evaluate the pioneer 166 herbs' slope's topmost horizons stabilisation potential using a limit equilibrium 167 method, which outcome will contribute to shed light on key plant-related data for 168 effective plant selection against shallow landslides and erosion.

2. Materials \& Methods

\subsection{Study site}

174 The study site lies within Catterline Bay, Northeastern Scotland, UK (WGS84 Long: 175 2.21 Lat: 56.90; Fig. 1), a region with mean annual temperature of $8.02{ }^{\circ} \mathrm{C}$ and mean 176 annual rainfall of $1232 \mathrm{~mm}$ (UK Met Office, 2015); constituting a humid temperate 177 climate site (Cfc: subpolar oceanic climate; Köppen, 1884). The precipitation is 


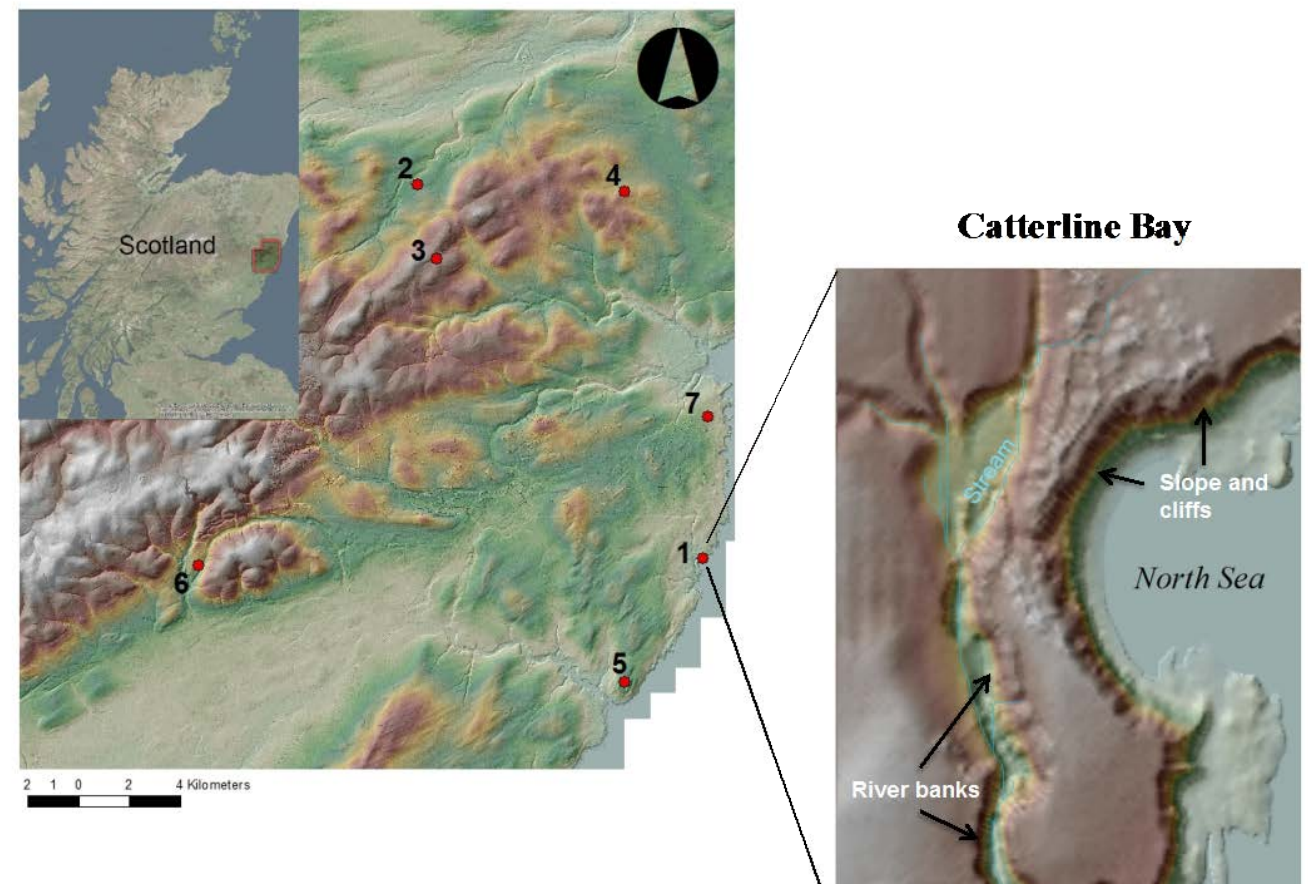

Figure 1. Study site location, topography, and location of the meteorological stations considered in this study. 1: Catterline; 2: Durris; 3: Mongour; 4: Netherley; 5: Inverbervie; 6: Fettercairn; 7: Stonehaven. Sloped terrain, cliffs and inclined riverbanks shown in darker shade/colour.

characterized by frequent, low-intensity rainfall events, while heavy storms seldom occur. The topography of the study site is dominated by sloped $\left(25-50^{\circ}\right)$ terrain and cliffs ending up into the sea, combined with a flatter inland area that is crossed by a small stream that leads to the formation of inclined river banks (Fig. 1). Shallow (ca. $600 \mathrm{~mm}$ ) and well-drained soils can be found within the study area resting on top of 183 sedimentary bedrock (i.e. conglomerate; BGS, 1999). The vegetation cover is dominated by herbaceous weeds and grasses, riparian trees and agricultural crops of wheat and barley. The sea has a limited influence on the vegetation as south-westerly winds prevail. Different soil mass wasting episodes (landslides and erosion) have 187 been reported on the site in the past (e.g. Kincardineshire Observer 11/4/2013), 188 mainly associated with prolonged rainfall periods. The failure zones are easily 189 identifiable, presenting exposed bare ground or areas of sparse vegetation 
193 The parameterisation process was carried according to the diagram shown in Fig. 2 in 194 order to identify and quantify the studied systems’ elements governing plant root 195 spread and feed a model aiming at providing root spread information in temperate 196 humid climates (i.e. root profile distribution model, RPDM; see 2.3).

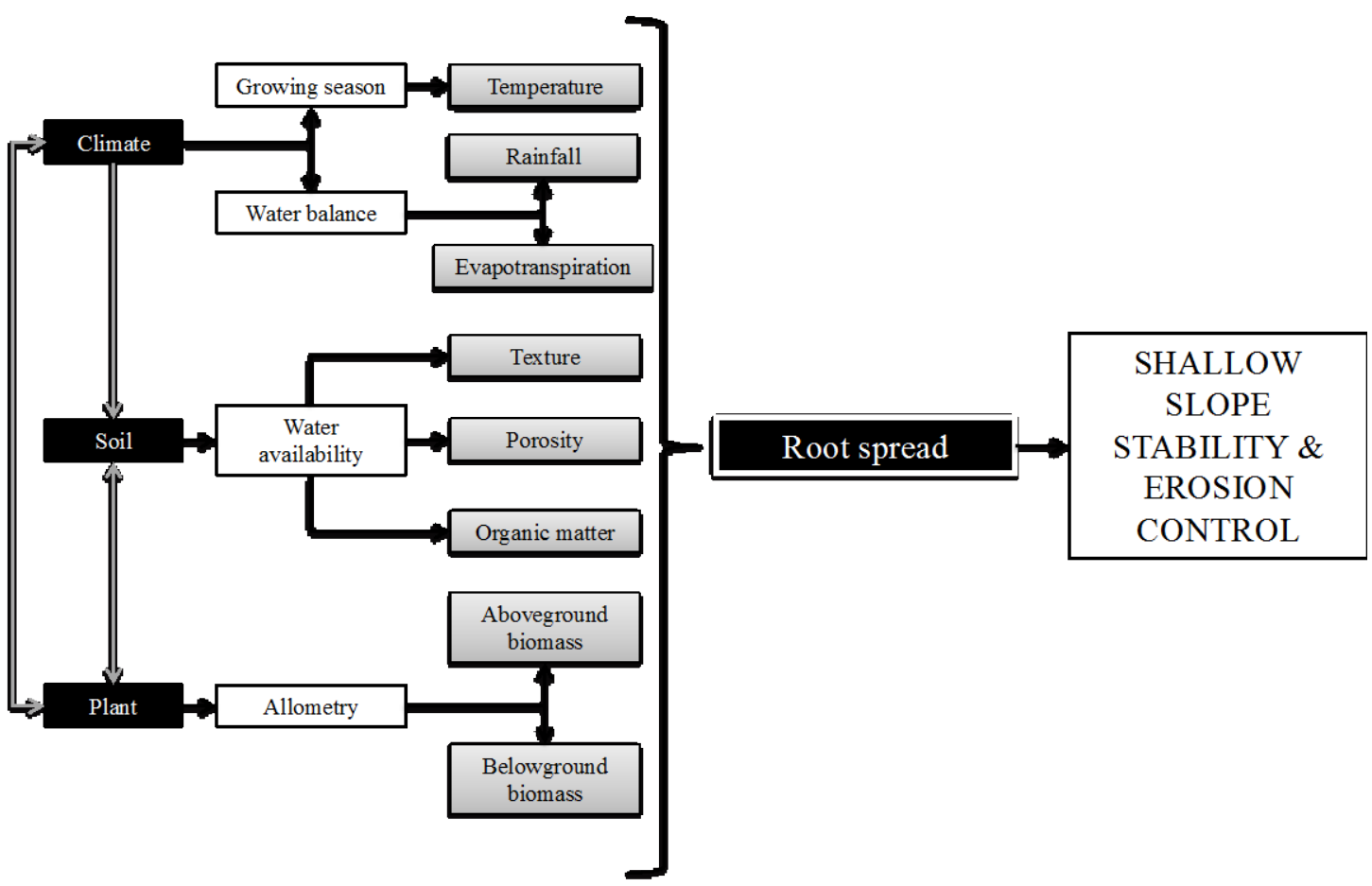

Figure 2. Arrow diagram showing the relationship between the considered compartments (black boxes) and parameters/variables (grey boxes) describing the root spread. Gray arrows indicate interactions between the compartments forming the ecosystem under study.

2.2.1 Climate parameters

203 Two types of climate data sets were employed: 1) short-term meteorological time 204 series from a meteorological station located at the study site (2012-2014; vor de Porte, 205 2015; Fig. 1; Point 1) 2) long-term meteorological time series belonging to 6 different 206 weather stations located within the region of the study site (1996-2014; UK Met Office, 2015; Fig. 1; Points 2 to 7). 
208 The growing season duration was determined according to the growing degree-days 209 (GDD) approach (e.g. McMaster \& Wilhelm, 1997). We assumed that the growing 210 season started once the cumulative GDD reached $200^{\circ} \mathrm{C}$, and that root growth was 211 inhibited when the daily air temperature was below $5^{\circ} \mathrm{C}$ (Alvarez-Uria and Körner, 212 2007). The duration of the growing season was estimated for each station and year 213 and then it was averaged for the considered time series.

214 The probability distribution of the rainfall intensity for each growing season was 215 assessed by estimating and plotting its kernel density (Parzen, 1962) in R 3.1.2 (R 216 Development Core Team, 2014). Then, the rainfall parameters $\lambda_{o}$ (i.e. frequency of 217 rainfall events) and $\alpha$ (i.e. mean rain intensity) were estimated for each growing 218 season as indicated in Preti et al. (2010). Both parameters, $\lambda_{o}$ and $\alpha$, were averaged 219 over the considered time series and compared against the values obtained at the study 220 site's station prior being used as input into RPDM (see 2.3). The mean 221 evapotranspiration rate $\left(T_{p}\left(\mathrm{~mm} \mathrm{~d}^{-1}\right)\right)$ over the growing season was estimated with 222 Priestly \& Taylor (1972) equation and the extension proposed by Savabi et al. (1989) 223 considering a broad-leaf vegetation cover (LAI: 3.48, Deguchi et al., 2006; 224 aboveground biomass $\left(M_{a}\right): 6140 \mathrm{~g} \mathrm{~m}^{-2}$, Nunes et al., 2013).

\subsubsection{Soil parameters}

228 Undisturbed soil core samples from the uppermost $150 \mathrm{~mm}$ were collected at 30 229 random locations within the study site using an aluminum core sampler of $95 \mathrm{~mm}$ 230 (inner diameter) and $150 \mathrm{~mm}$ (height). The soil samples were oven-dried at $110^{\circ} \mathrm{C}$ 231 over 24 hours to calculate the dry bulk density and porosity; assuming a soil particle 232 density of $2.65 \mathrm{~g} \mathrm{~cm}^{-3}$ (Head, 1980). The soil particle size distribution was determined 
233 by the dry sieving method and by the hydrometer method for the coarse (i.e. gravel 234 and sand) and the fines fraction (i.e. silt and clay), respectively (BS 1377 Part

235 2:1990). Soil organic matter content was estimated through the loss on ignition 236 method (Schulte and Hopkins, 1996). Soil saturated hydraulic conductivity was 237 measured at 5 different locations with a constant head Guelph permeameter (Reynolds 238 and Elrick, 1990). The former soil parameters were used to determine the soil's field 239 capacity $\left(\theta_{f c}\right)$ and wilting point $\left(\theta_{w p}\right)$ by means of pedotransfer functions (Toth et al., 240 2015). The mean $\theta_{f c}$ and $\theta_{w p}$ values between the sampled points was employed as 241 input into RPDM (see 2.3).

\subsubsection{Plant parameters}

Three different dominant species of perennial pioneer herbs were selected (Table 1)

246 for parameterisation. All of them are native species that are well distributed over the 247 entire UK, generally colonizing disturbed grounds (Perring and Walters, 1982). Plant 248 sampling was carried at the height of the 2014's growing season (i.e. late July-early 249 August) in which ten to eleven individuals of each species were sampled at random 250 locations within the study site. Each plant individual was carefully excavated by hand 251 without separating the above and belowground parts. In addition, to quantify the plant 252 cover in terms of the aboveground biomass and the abundance of the selected plant 253 species, twenty-five $1 \mathrm{~m}^{2}$ quadrants were randomly sampled within the study site 254 (USDA-NRCS, 1997).

255 Table 1. Studied herbaceous plant species.

\begin{tabular}{lll}
\hline Species & Family & Common name \\
\hline Erigeron acris L. & Asteraceae & Blue fleabane \\
Rumex obtusifolius L. & Polygonaceae & Broad-leaved dock \\
Silene dioica Clariv. & Caryophyllaceae & Red campion \\
\hline
\end{tabular}


257 Each plant individual was clipped 2 millimetres above the collar with precision 258 scissors to separate the above from the belowground part. The biomass of the above 259 and belowground plant parts was determined after oven drying at $70^{\circ} \mathrm{C}$ for 48 hours.

260 The relationship between above and belowground parts (i.e. plant allometry) was 261 evaluated through the implementation of exponential regression models in $\mathrm{R}$ 3.1.2, 262 assuming a power-law relationship between both plant vegetative parts (WBE model;

263 West et al., 1997; Cheng and Niklas, 2007) of the form $M_{a}=\beta M_{r}{ }^{\alpha}$, where $M_{a}$ and $M_{r}$ 264 are the above and belowground biomass (g), respectively, $\beta$ is the allometric 265 normalization constant.

2.2.4. Root spread parameters

269 To estimate the root cross-sectional area with soil depth (i.e. rooted soil), the root 270 diameters $\left(d_{i}\right)$ for each depth interval were summed up and the area was then 271 calculated as $A_{\mathrm{i}}=\pi\left(\sum d_{\mathrm{i}} / 2\right)^{2}$, assuming that the soil-rooted area approaches a 272 circumference at every considered depth and that fine roots are randomly distributed 273 within. The average of all observations at every depth for each plant species were 274 considered, to which an exponential regression model was fitted in $\mathrm{R}$ 3.1.2. The 275 proportion of root-reinforced soil (i.e. root area ratio; $R A R$ ) was then calculated as $276 R A R(\mathrm{z})=A_{\mathrm{i}}(\mathrm{z}) / A_{\text {soil }}$. The mean rooting depth (b) was estimated as the average of the 277 total rooting depth of all individuals per species divided by 3 (Laio, 2006). The root 278 cross-sectional area at the ground level $\left(\mathrm{Ar}_{\mathrm{o}}\right)$ was assessed like $A_{i}$ but considering the 279 root diameters at the root collar.

2812.3 Root profile distribution model (RPDM) for temperate humid climates. 


\subsubsection{Model description}

The eco-hydrological model RPDM for temperate humid climates was based on Laio's et al. (2006) model concept for the determination of the mean rooting depth $(b)$ 287 at the plant community level for water-limited ecosystems. The former model (Laio et al., 2006) estimates $b(\mathrm{~mm})$ as a function of the long-term water balance in the soil by considering the ratio between the incoming water (i.e. rainfall) to the soil's available water content (AWC) to plants, where AWC is in turn constrained by the atmospheric 291 water demand during the growing season - i.e. $b=\alpha / n\left(\theta_{f c}-\theta_{w p}\right)\left(1-\alpha \lambda{ }_{o} / T_{p}\right)$.

292 Contrariwise, we assumed herein that water income is no longer a limiting resource in 293 the soil profile for root system spread as, in temperate humid climates, precipitation 294 tends to be plentiful while evapotranspiration, or atmospheric water demand, is kept 295 at relatively low level (Allen et al., 1998). Therefore, we simplified Laio’s analytical model by considering that all the soil's incoming water would potentially be available

297 to plants. Hence, the mean rooting depth was estimated as:

$$
b=\frac{\alpha}{n(\theta f c-\theta w p)}
$$

298 where $\alpha$ is the mean rainfall intensity per event (mm/event) over the growing season 299 (see 2.2.1), and $n\left(\theta_{f c}-\theta_{w p}\right)$ is the soil's available water content (AWC) to plants, being $300 n$ is the soil porosity (unitless), $\theta_{f c}$ is the soil's volumetric moisture content at field 301 capacity and $\theta_{w p}$ the soil's volumetric moisture content at wilting point (see 2.2.2). 302 Therefore, the mean rooting depth (b) would be just constrained by the soil 303 hydrological properties and fostered by the mean rainfall intensity during the growing season $(\alpha)$. With this, it is also assumed that, according to hydrotropism principles 
(e.g. Tsutsumi et al., 2003), the extent to which water can infiltrate in the soil profile is key to determining the extent of root profiles (Laio et al., 2006) and that evapotranspiration does not limit the availability of water to plants in temperate

308 humid climates. Having estimated $b$, the soil depth at which the $95 \%$ (i.e. $Z_{95}$ ) of the 309 roots can be found can be calculated as $Z_{95}=3 b$ (Laio et al., 2006).

310 The root distribution profile, or root spread, was considered to decrease exponentially 311 with the soil depth (z); assuming that the probability distribution of the rainfall 312 intensity was also exponential (Laio et al., 2006; see 2.2.1) and portrayed by $313 \operatorname{Ar}(\mathrm{z})=A r_{o} \exp ^{-z / b}$ (Preti et al., 2010). Where $\operatorname{Ar}(\mathrm{z})$ is the root cross-sectional area with 314 soil depth $\left(\mathrm{mm}^{2}\right), A r_{o}$ is the root cross-sectional area at the ground level $\left(\mathrm{mm}^{2}\right), z$ is 315 the soil depth (mm) and $b$ the mean rooting depth (mm). Assuming a conical shape 316 root system, $A r_{o}$ was estimated from the plant aboveground biomass $\left(M_{a}\right)$, allometric 317 parameters ( $\beta$ and $\alpha$; see 2.2.3), the mean rooting depth $(b)$ and root mass density $\left(\rho_{\mathrm{r}}\right)$ $318\left(A r_{o=} \beta M_{a}^{1 / \alpha^{\prime}} / b \rho_{\mathrm{r}}\right.$; Preti et al., 2010). Eventually, the root area ratio $(R A R(\mathrm{z}))$ was 319 estimated (see 2.2.3) .

\subsubsection{Model quality}

The goodness of fit of RPDM was quantified through the estimation of the coefficient

324 of determination $\left(\mathrm{R}^{2}\right)$ by subtracting from 1 the quotient between the residual (i.e. 325 difference between observed and predicted values) sum of squares and explained sum 326 of squares (i.e. $\mathrm{R}^{2}=1-\mathrm{SS}_{\mathrm{res}} / \mathrm{SS}_{\mathrm{obs}}$; e.g. Bivand et al., 2008). In addition, statistically 327 significant differences between observed and regressed values for the parameters $A r_{o}$ 328 and $b$ were assessed with the chi-square $\left(\chi^{2}\right)$ test at the $95 \%$ and $99 \%$ confidence 329 intervals in R 3.1.2. 
333 The sensitivity of RPDM was analyzed with the One-factor-At-a-Time approach

334 (OAT; Daniel, 1973), considering the mean root cross-sectional area as the model 335 output. The 9 independent model parameters (Table 2) were considered and their base 336 value was varied $\pm 20 \%$ to account for natural variability. One model run was carried 337 for each parameter value change (i.e. 18 model runs in total). The parameter change 338 that generated the greatest output variation with respect to the original model run was 339 kept for the estimation of the sensitivity index (SI) and the percentage of variation 340 (PV) (Felix \& Xanthoulis, 2005). Finally, the effect of the most sensitive parameters 341 on the root distribution profiles was evaluated and discussed.

342 Table 2. RPDM’s independent parameters considered within the sensitivity analysis.

\begin{tabular}{ll}
\hline Symbol & Parameter \\
\hline$M_{a}$ & Plant's aboveground biomass (g) \\
$\alpha$ & Allometric power-law parameter \\
$\beta$ & Allometric parameter \\
$\rho_{r}$ & Root mass density $\left(\mathrm{g} \mathrm{cm}^{-3}\right)$ \\
OM & Soil's organic matter content (\%) \\
Silt & Soil's silt content (\%) \\
Clay & Soil's clay content (\%) \\
$n$ & Soil porosity (unitless) \\
$\alpha$ & Mean rain intensity during growing \\
& season (mm $\left.\mathrm{H}_{2} \mathrm{O} / \mathrm{event}\right)$ \\
\hline
\end{tabular}

RPDM expansion was carried using the 'raster stack' concept (a collection of raster layers with the same spatial extent and resolution) of the R's package 'raster'

349 (Hijmans, 2014). Thus, we modeled a given soil column, of a pixel size area (i.e. raster resolution), as the pool of superimposed raster pixels for a given XY coordinate 
351 within a given raster stack (Fig. 3). The range of depths for a given soil profile was

352 then portrayed by each layer in the stack; assigning the same z-value (depth) to every

353 pixel belonging to the same stack layer. This approach makes also possible to assign

354 different attributes to each layer in order to mimic the features of different soil

355 horizons. However, isotropic soil profiles were considered herein for the sake of

356 simplicity.

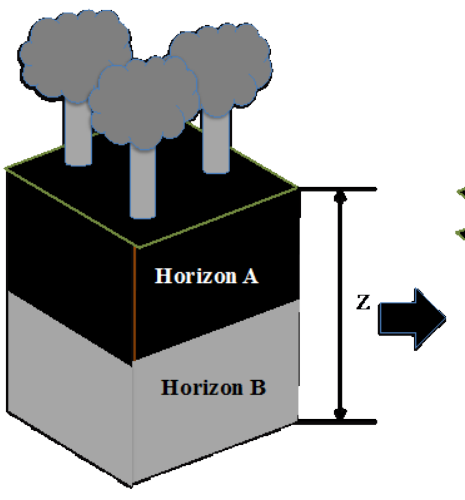

Soil column

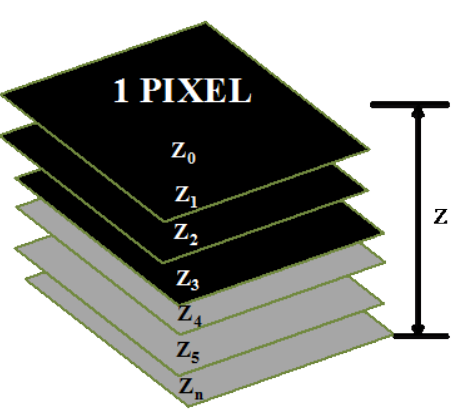

1 PIXEL

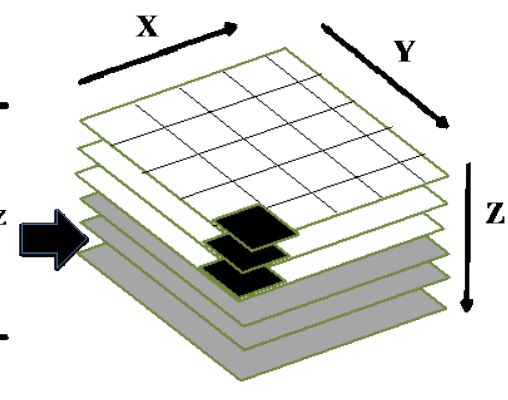

Raster stack

Figure 3. Illustration of how RPDM-3D models a given soil column. Each pixel portrays a different soil column of area the pixel size. Each soil column may have a custom number of layers, each portraying a different soil depth $\left(\mathrm{z}_{\mathrm{n}}\right)$ or additional customizable soil attributes that vary with soil depth. The pool of soil layers is combined in a raster stack formed by the superposition of raster layers.

The spatially distributed RPDM was tested on our study site (i.e. Catterline bay; Fig. 1), where the root spread and, its corresponding effect on slope stability (see 2.4), were retrieved from 4 randomly selected pixels. Soil spatial inputs to RPDM were obtained by spatially interpolating the measured soil parameters (see 2.2.2). The spatial interpolations were carried with the machine learning algorithm 'Random Forest' (RF) (Breiman, 2001) using terrain attributes (i.e. slope, aspect, curvature and shade) and plant cover as environmental spatial covariates (Table 3); following the principles of the 'scorpan' approach (Jenny, 1941). The terrain attributes were derived from a 2m digital surface model (DSM) (GetMapping, 2014) using the 3D 
371 validated using a random-hold back, or bootstrapping method (Efron, 1979), through

372 the estimation of $\mathrm{R}^{2}$ as indicated in 2.3.2.

373 Table 3. Soil spatial prediction formulas and environmental covariates implemented with the RF algorithm for

374 each of the considered soil spatial variables.

\begin{tabular}{ll}
\hline Spatial variable & Formula and environmental covariates \\
\hline Soil sand content (\%) & Sand=Slope+Aspect+Curvature+Plant cover \\
Soil fines content $(\%)$ & Fines=Slope+Aspect+Curvature+Plant cover \\
Soil silt content $(\%)$ & Silt=Slope+Aspect+Curvature+Plant cover \\
Soil clay content $(\%)$ & Clay=Fines-Silt \\
Soil organic matter (\%) & OM=Slope+Aspect+Curvature+Plant cover+Sand \\
Dry bulk density $\left(\mathrm{g} / \mathrm{m}^{3}\right)$ & Bulk=Slope+Aspect+Curvature+Plant cover+Sand+Fines+OM \\
Plant biomass $\left(\mathrm{g} / \mathrm{m}^{2}\right)$ & Biomass=Slope+Aspect+Curvature+Shade+Sand+Fines+OM+Plant cover \\
\hline
\end{tabular}

2.4. Root mechanical effect against shallow landslides

To assess the soil-root mechanical reinforcement effect against shallow landslides, the retrieved root spread information was employed to estimate the apparent root

381 cohesion $\left(\mathrm{C}_{\mathrm{R}}(\mathrm{z})\right)$ with the widely used simple perpendicular model (SPM; Waldron, 382 1977; Wu et al., 1979), which requires a measurement or estimation of the root area 383 ratio $(R A R(\mathrm{z}))$ and the mean root tensile strength $\left(T_{r}\right)$ as input. $c_{R}(\mathrm{z})$ was directly 384 added to the resisting forces (Wu et al., 1979; Ekanayake and Phillips, 2002; Norris et 385 al., 2008) for the estimation of a factor of safety (FoS(z)= $386 C_{R}(\mathrm{z})+$ resisting $\left.(\mathrm{z}) / \operatorname{driving}(\mathrm{z})\right)$ using an infinite slope limit equilibrium method (LEM; 387 Lu and Godt, 2008). The former LEM method (Lu and Godt, 2008) does not require 388 assuming the location of a particular critical plane of failure. Instead, the latter is 389 detected in light of the soil's hydro-mechanical properties and conditions. However, a 390 lower boundary for the system under study was arbitrarily set at $500 \mathrm{~mm}$ below the 391 ground level (b.g.l), far below the expected reach of the herbaceous root systems in 392 order to avoid edge effects. 
393 The values of $T_{r}$ were as per the reported values in literature (i.e. $T_{r}^{\text {herbs }}=3.73 \mathrm{MPa}$, 394 Comino et al., 2010). RAR(z) for each studied herb species was derived from the total 395 aboveground biomass per unit area $\left(M_{a}{ }^{T}\right)$ using the plant cover and abundance (see 396 2.2.3) from the two quadrants where the selected species were the most abundant.

397 The studied species' soil-root reinforcement was compared against the effect provided 398 by an oak tree (Quercus robur L.; $T_{r}{ }^{o a k}=8.00 \mathrm{MPa}$, Stokes et al., 2008; $\mathrm{M}_{\mathrm{a}}=6300 \mathrm{~g} \mathrm{~m}^{-}$ 3992 , Nunes et al., 2013; $\alpha^{\prime}=0.8 \beta=3.42$, Cheng and Niklas, 2007) and bare soil. To stress 400 the soil-root reinforcement effect, cohesionless and hydrostatic soil conditions were 401 assumed.

402 Statistically significant differences between the treatments were evaluated with a 403 Kruskal-Wallis test among the winsorized means (Wilcox and Keselman, 2003) of 404 FoS trimmed at 20\% and at the 95 and 99\% confidence intervals.

3. Results

3.1. Parameterisation

412 Climate parameterisation results (Table 4) show that the mean annual rainfall (R) for 413 the study site was the lowest of all considered stations (i.e. $565.13 \pm 46.89 \mathrm{~mm}$ ) while 414 the annual evapotranspiration (ETP) was the highest $(489.38 \pm 4.29 \mathrm{~mm})$. All stations 415 presented higher $\mathrm{R}$ respect to ETP. The mean rainfall intensity per event $(\alpha)$ ranged 416 between 3.20 and $9.14 \mathrm{~mm}$, belonging the lowest found to the study site. The growing 417 season duration would last from mid-late May to mid October for all considered 
study site.

Table 4. Calculated climatic features and mean growing season duration (GSD) for each meteorological station. $\alpha$ : mean rainfall intensity per event \pm standard error; $\lambda_{0}$ : frequency of rainfall event \pm standard error; $R$ : mean annual rainfall \pm standard error; ETP : mean annual evapotranspiration \pm standard error.

\begin{tabular}{|c|c|c|c|c|c|c|c|}
\hline Station & $\begin{array}{c}\text { Distance } \\
(\mathrm{km})\end{array}$ & Period & $\begin{array}{l}\text { (mm per } \\
\text { event) }\end{array}$ & $\lambda_{0}$ & $\mathrm{R}(\mathrm{mm})$ & ETP (mm) & $\begin{array}{c}\text { GSD } \\
\text { (day/month) }\end{array}$ \\
\hline Catterline & & 2012-2014 & $\begin{array}{c}3.20 \pm \\
0.38\end{array}$ & $\begin{array}{c}0.64 \pm \\
0.02\end{array}$ & $\begin{array}{c}565.13 \pm \\
46.89\end{array}$ & $\begin{array}{c}489.38 \pm 1 \\
4.29\end{array}$ & $23 / 5-11 / 11$ \\
\hline Durris & 19.6 & 1996-2014 & $\begin{array}{c}5.33 \pm \\
0.32\end{array}$ & $\begin{array}{c}0.54 \pm \\
0.02\end{array}$ & $\begin{array}{c}1020.15 \pm \\
40.35\end{array}$ & $\begin{array}{c}461.69 \pm \\
10.77\end{array}$ & $11 / 5-14 / 10$ \\
\hline Mongour & 15.8 & 1996-2014 & $\begin{array}{c}9.86 \pm \\
1.83\end{array}$ & $\begin{array}{c}0.72 \pm \\
0.05\end{array}$ & $\begin{array}{c}1011.52 \pm \\
113.01\end{array}$ & $\begin{array}{c}468.08 \pm \\
8.80\end{array}$ & $29 / 5-7 / 10$ \\
\hline Netherley & 14.9 & 1996-2013 & $\begin{array}{c}5.07 \pm \\
0.30\end{array}$ & $\begin{array}{c}0.64 \pm \\
0.02\end{array}$ & $\begin{array}{c}1022.22 \pm \\
88.39\end{array}$ & $\begin{array}{c}461.54 \pm \\
10.26\end{array}$ & $13 / 5-16 / 10$ \\
\hline Inverbervie & 5.8 & 1997-2007 & $\begin{array}{c}9.14 \pm \\
0.72\end{array}$ & $\begin{array}{c}0.66 \pm \\
0.02\end{array}$ & $\begin{array}{c}1905.74 \pm \\
153.41\end{array}$ & - & - \\
\hline Fettercairn & 19.9 & $1996-2014$ & $\begin{array}{c}4.66 \pm \\
0.27\end{array}$ & $\begin{array}{c}0.62 \pm \\
0.01\end{array}$ & $\begin{array}{c}971.31 \pm \\
48.35\end{array}$ & - & - \\
\hline Stonehaven & 5.7 & 1996-2013 & $\begin{array}{c}3.76 \pm \\
0.29\end{array}$ & $\begin{array}{c}0.57 \pm \\
0.02\end{array}$ & $\begin{array}{c}747.00 \pm \\
52.15\end{array}$ & $\begin{array}{c}438.19 \pm \\
24.41\end{array}$ & $17 / 5-23 / 10$ \\
\hline
\end{tabular}

423

Rainfall distribution function

(a)

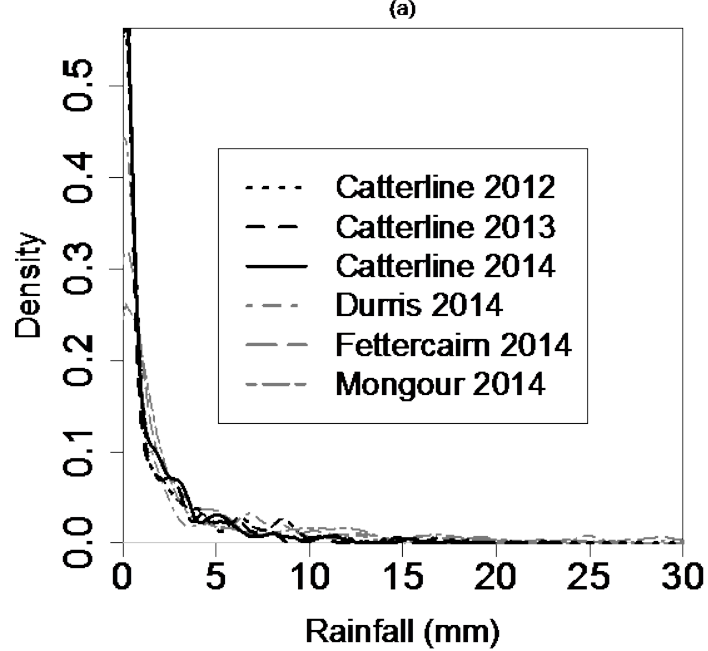

Monthly rainfall (1996-2014)

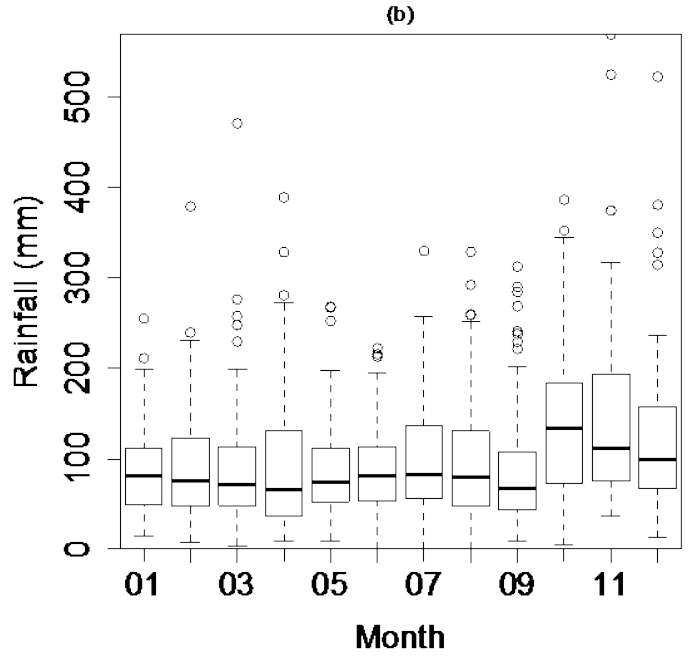

Figure 4. a) Rainfall intensity probability distribution functions for the study site (2012-2014) and a three other meteorological stations for the year 2014 b) Monthly rainfall distribution throughout the year averaged per meteorological station between all the studied time series, where the bottom and top of the boxes represent the first and third quartiles, respectively, the band inside the box represents the median, and the points represent outliers from all the studied time series. 
The soil parameterisation results (Table 5) indicated that relatively porous, silty sands

431 (Craig, 2004), with high organic matter content (Urbano, 1992) and good drainage conditions (Head and Epps, 2011) can be found within our study site..

Table 5. Measured mean value for each of the considered soil variables averaged between the sampling points and standard errors. OM: organic matter content; $\rho_{\mathrm{b}}$ soil bulk density; n: soil porosity; Ks: saturated hydraulic conductivity; $\theta_{\mathrm{fc}}$ : volumetric moisture content at field capacity; $\theta_{\mathrm{wp}}$ : volumetric moisture content at wilting point.

\begin{tabular}{lllllllll}
\hline Sand (\%) & Silt (\%) & Clay (\%) & OM $(\%)$ & $\rho_{\mathrm{b}}\left(\mathrm{g} / \mathrm{cm}^{3}\right)$ & $\mathrm{n}$ & $\mathrm{Ks}(\mathrm{m} / \mathrm{s})$ & $\theta_{\mathrm{fc}}$ & $\theta_{\mathrm{wp}}$ \\
\hline 74.97 & 2.87 & 1.60 & 5.57 & 0.86 & 0.68 & $5.82 \mathrm{e}-5$ & 0.23 & 0.09 \\
\pm 2.47 & \pm 0.19 & \pm 0.12 & \pm 0.65 & \pm 0.06 & \pm 0.02 & $\pm 1.43 \mathrm{e}-5$ & \pm 0.003 & \pm 0.001 \\
\hline
\end{tabular}

3.1.3 Plant parameters

Results from the plant parameterisation (Table 6) show that the aboveground dry

441 biomasas $\left(\mathrm{M}_{\mathrm{a}}\right)$, at the individual level, and for the three studied herb species, ranged

442 between $14.20 \pm 1.45 \mathrm{~g}$ (E. acris) and 27.65 $\pm 8.66 \mathrm{~g}$ ( $R$. obtusifolius). The belowground

443 dry biomass $\left(\mathrm{M}_{\mathrm{r}}\right)$, however, ranged between $1.65 \pm 0.71 \mathrm{~g}($ S. dioica) and $13.36 \pm 4.05 \mathrm{~g}$

444 (R. obtusifolius). The plant abundance in the study site (A; Table 6) varied between $21.50 \%$ (S. dioica) and $10.87 \%$ (E. acris).

The allometric parameters ( $\alpha$ ' and $\beta$; Table 6 ) were different for all the studied herbs

447 and only Erigeron acris presented an exponential allometric relationship between $\mathrm{M}_{\mathrm{a}}$

448 and $\mathrm{M}_{\mathrm{r}}\left(\alpha^{\prime}=0.43 ; \beta=9.06 ; \mathrm{R}^{2}=0.65\right.$; Figs. $\left.6 \mathrm{~d}-\mathrm{f}\right)$ while the other two species shown a

449 linear relationship (Figs. 6d-f) with a higher goodness of fit (i.e. $\mathrm{R}^{2} \geq 0.95$; Table 6).

\subsubsection{Root spread parameters}

453 The measured mean rooting depth (Table 6) spanned from $21.21 \pm 3.52 \mathrm{~mm}$ (S. dioica)

454 to $45.45 \pm 2.82 \mathrm{~mm}$ (R. obtusifolius). The species that presented the largest root crosssectional area at the ground level $\left(A r_{o}\right)$ was Rumex obtusifolius $\left(747.08 \pm 301.58 \mathrm{~mm}^{2}\right)$. 


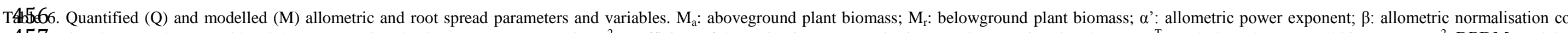

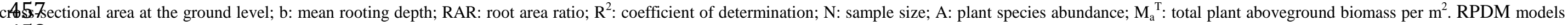

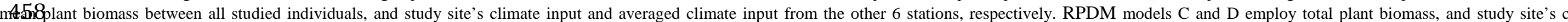
aA5iged climate input from the other 6 stations, respectively. Q: mean \pm standard error

\begin{tabular}{|c|c|c|c|c|c|c|c|c|c|c|c|c|c|}
\hline Species & Type & Model & $\mathrm{M}_{\mathrm{a}}(\mathrm{g})$ & $\mathrm{M}_{\mathrm{r}}(\mathrm{g})$ & $\alpha^{\prime}$ & $\beta$ & $\mathrm{Ar}_{0}\left(\mathrm{~mm}^{2}\right)$ & $\mathrm{b}(\mathrm{mm})$ & RAR (\%) & $\mathrm{R}^{2}$ & $\mathrm{~N}$ & $\mathrm{~A}(\%)$ & $\mathrm{M}_{\mathrm{a}}^{\mathrm{T}}\left(\mathrm{g} \mathrm{m}^{-2}\right)^{\mathrm{b}}$ \\
\hline \multirow[t]{5}{*}{ E. acris } & $\mathrm{Q}$ & & $14.20 \pm 1.45$ & $3.14 \pm 0.67$ & - & - & $178.33 \pm 55.58$ & $40.74 \pm 5.82$ & $3.68 \times 10^{-3} \pm 5.52 \times 10^{-5}$ & & 10 & $10.87 \pm 0.79$ & 325 \\
\hline & M & Allometric & - & - & 0.43 & 9.06 & - & - & - & 0.65 & - & - & - \\
\hline & M & Regression & - & - & - & - & 125.23 & 45.91 & - & 0.96 & - & - & - \\
\hline & M & RPDM A & - & - & - & - & 78.55 & 45.48 & - & 0.74 & - & - & - \\
\hline & M & RPDM B & & & - & - & 41.03 & 87.08 & - & 0.43 & - & - & - \\
\hline \multirow[t]{5}{*}{ R.obtusifolius } & $\mathrm{Q}$ & & $27.65 \pm 8.66$ & $13.36 \pm 4.05$ & & & $747.08 \pm 301.58$ & $45.45 \pm 2.82$ & $1.88 \times 10^{-2} \pm 2.30 \times 10^{-4}$ & & 11 & $20.41 \pm 1.58$ & 1400 \\
\hline & M & Allometric & - & - & 0.99 & 2.13 & - & - & - & 0.95 & - & - & - \\
\hline & M & Regression & - & - & - & - & 566.15 & 56.54 & - & 0.93 & - & - & - \\
\hline & M & RPDM A & - & - & - & - & 366.10 & 45.48 & - & 0.61 & - & - & - \\
\hline & M & RPDM B & - & - & - & - & 191.24 & 87.07 & - & 0.32 & - & - & - \\
\hline \multirow[t]{7}{*}{ S. dioica } & $\mathrm{Q}$ & & $16.74 \pm 7.61$ & $1.65 \pm 0.71$ & - & - & $541.13 \pm 136.53$ & $21.21 \pm 3.52$ & $1.79 \times 10^{-2} \pm 4.15 \times 10^{-4}$ & & 11 & $21.50 \pm 2.12$ & 325 \\
\hline & M & Allometric & - & - & 1.021 & 10.07 & - & - & - & 0.98 & - & - & - \\
\hline & M & Regression & - & - & - & - & 443.81 & 35.52 & - & 0.99 & - & - & - \\
\hline & M & RPDM A & - & - & - & - & 45.20 & 45.48 & - & 0.19 & - & - & - \\
\hline & M & RPDM B & - & - & - & - & 23.61 & 87.08 & - & 0.19 & - & - & - \\
\hline & M & RPDM C & - & - & - & - & 473.30 & 45.48 & - & 0.83 & - & - & - \\
\hline & M & RPDM D & - & - & - & - & 247.23 & 87.08 & - & 0.66 & - & - & - \\
\hline
\end{tabular}

460 a RAR: mean percentage \pm standard error of all the studied plant individuals between the depths 0-250 mm for E.acris, 0-200 mm for R. obtusifolius and 0-170 mm for S.dioica.

$461{ }^{\mathrm{b}} \mathrm{M}_{\mathrm{a}}^{\mathrm{T}}$ : mean of the total aboveground biomass found at the two quadrants in which the considered plant species was the most abundant. 
464 The mean RAR between the considered depths (Table 6) ranged between 3.68x10

$465{ }^{3} \pm 5.52 \times 10^{-5} \%$ and $1.88 \times 10^{-2} \pm 2.3 \times 10^{-4} \%$ for E. acris and $R$. obtusifolius, respectively.

(a)

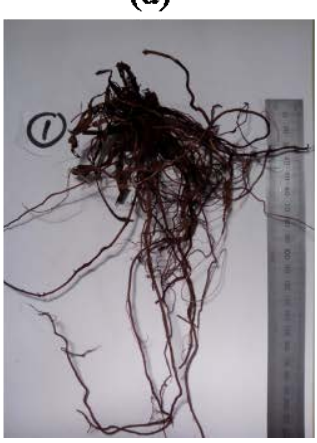

(b)

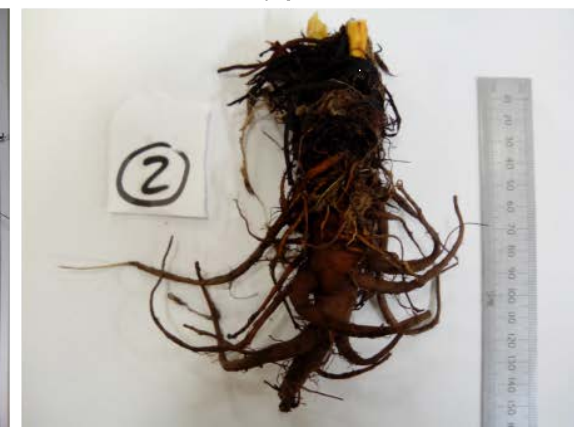

(c)

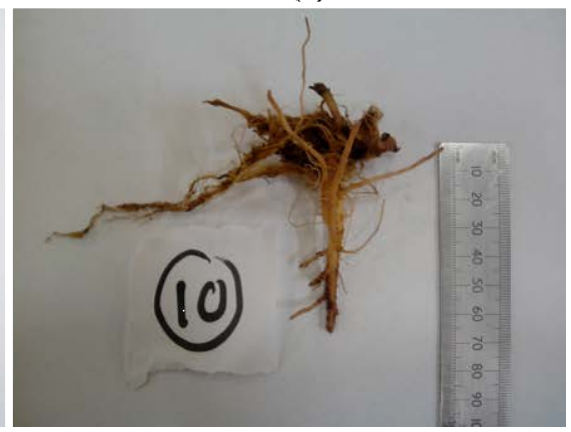

Figure 5. Selected root systems of a) Erigeron acris b) Rumex obtusifolius c) Silene dioica

470 The root systems (Fig. 5) for the three studied species (Table 1) presented clear morphological differences. Regarding the root spread (Figs. 6a-c), the three species shown a decreasing exponential profile distribution with soil depth to which an exponential regression model was fitted with a goodness of fit $\left(\mathrm{R}^{2}\right)$ above 0.9 in all cases (Table 6). All root systems investigated were distributed within the uppermost $300 \mathrm{~mm}$ of the soil profile, with the deepest root system belonging to Rumex obtusifolius (Fig. 6b)

RPDM predictions for the root spread parameters, $b$ and $A r_{o}$, and their respective predictive capacities, are gathered in Table 6. RPDM predicted values for both parameters that did not significantly differ $\left(\chi^{2}=1.66, \mathrm{df}=2 ; \chi^{2}=1.34, \mathrm{df}=2\right)$ from the observed and regressed counterparts (Table 6) when the study site's meteorological

481 inputs were employed. 

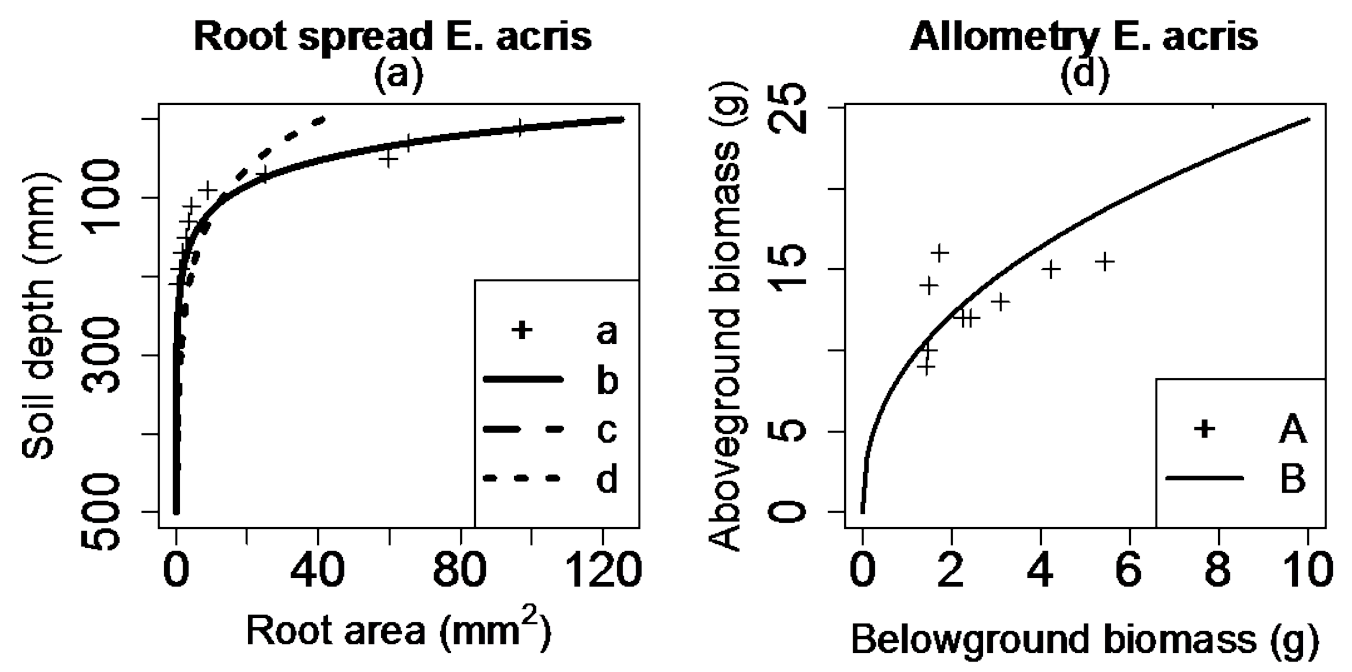

Root spread R. obtusifolius (b)
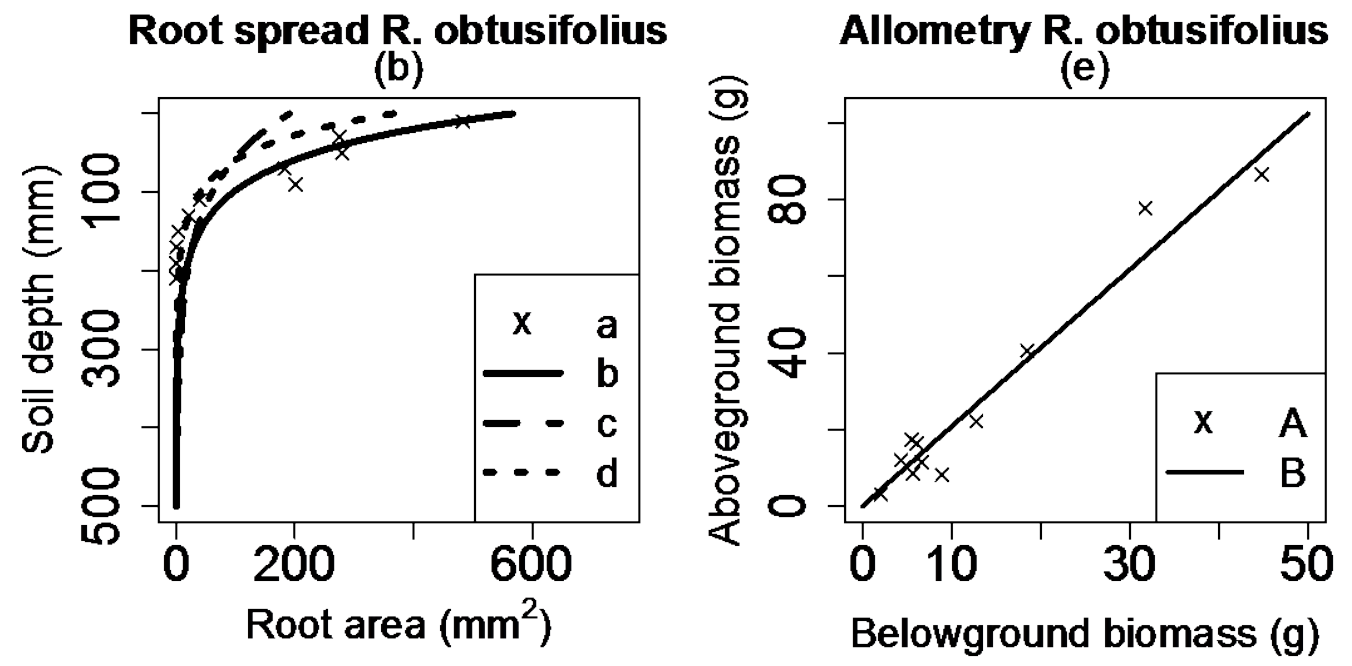

Root spread S. dioica
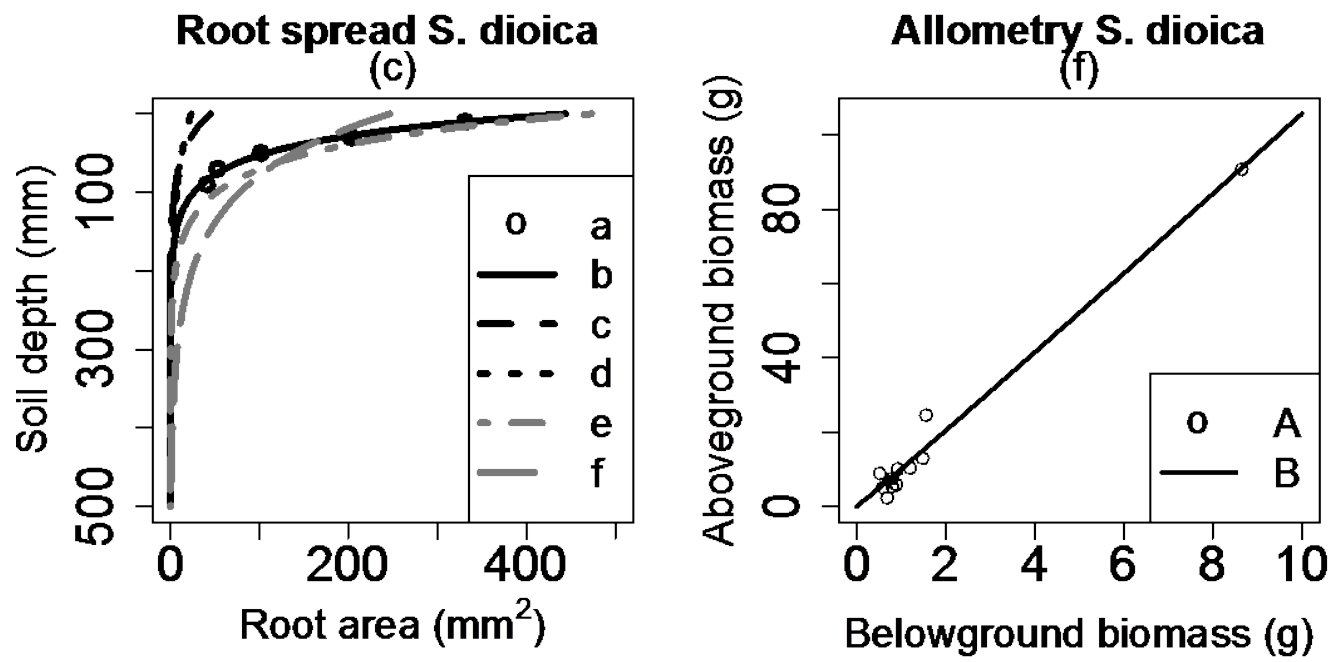

Figure 6. a-c) Measured and predicted root spread for d) E. acris e) R. obtusifolius f) S. dioica, where a: observed values; b: regressed values; c: predicted values from RPDM using study site's climate input; d: predicted values from RPDM using averaged climate inputs from the other 6 weather stations; e and f: predicted values from RPDM using the total biomass of all studied individuals of $S$. dioica and, study site's climate input and rest of the stations input, respectively d-f) Measured allometric relationships between aboveground and belowground vegetative parts for a) E. acris b) R. obtusifolius c) S. dioica, where A: observed values; B: fitted values. 
489 Sensitivity analysis outcomes for RPDM are presented in Figs. 7a-d, being the 490 allometric parameter $\beta$ (PI=68 \%; SI=-2.28), the plant's aboveground biomass $\left(M_{a}\right.$; $491 \mathrm{PV}=52.8 \%$; SI=2.29) and the mean rainfall intensity during the growing season $(\alpha$; $492 \mathrm{PV}=30.22 \%$; $\mathrm{SI}=-1.18$ ) the three most sensitive parameters upon predicting root spread.

Percentage of variation

(a)

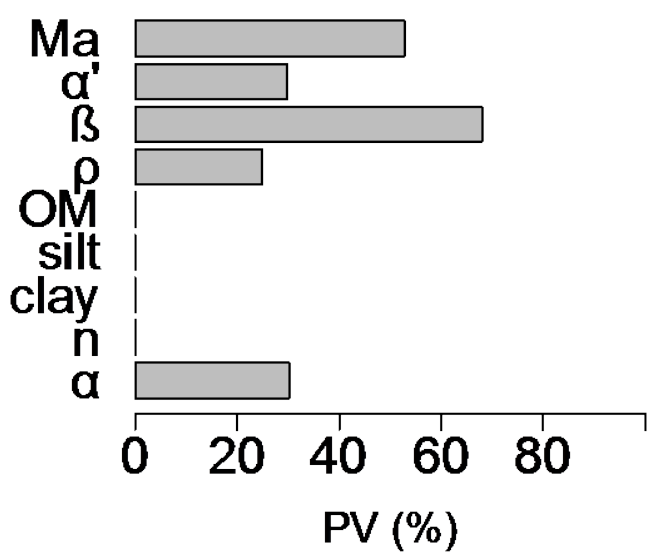

RPDM sensitivity

(c)

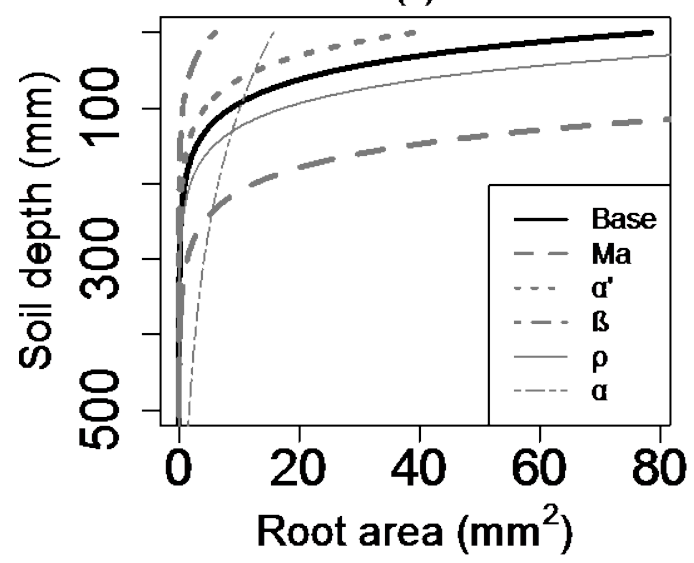

Sensitivity Index

(b)

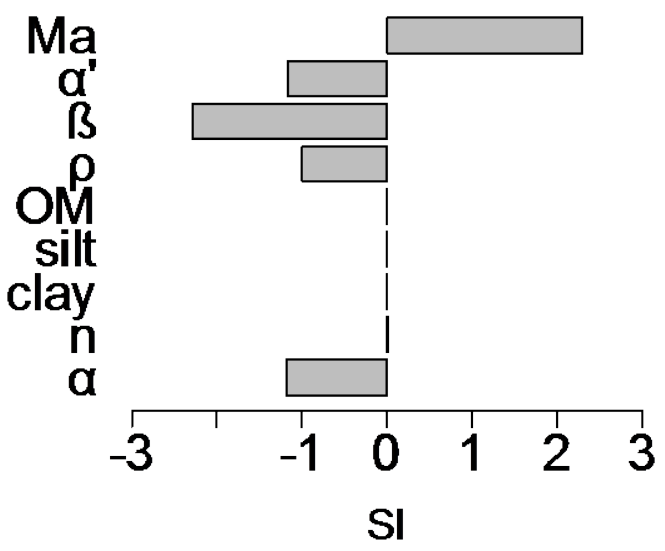

RPDM sensitivity

(d)

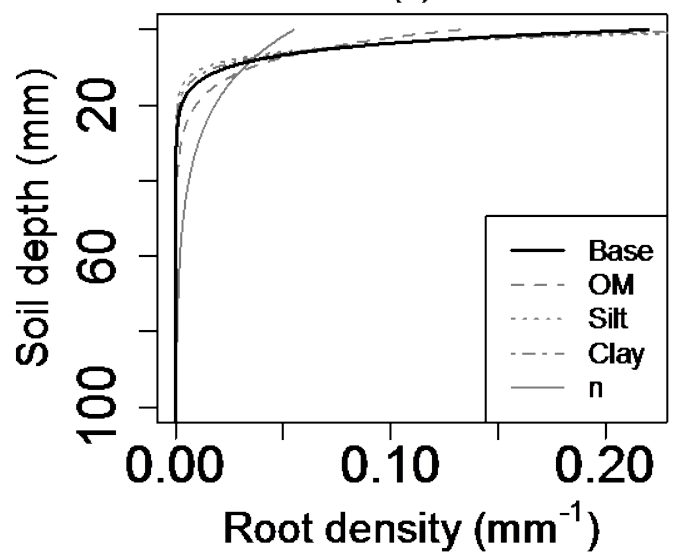

Figure 7. Sensitivity analysis outcome for RPDM a) Percentage of variation (PV) b) Sensitivity index (SI) c) RPDM output for the base model run and after applying value changes to the most sensitive parameters respect to the base model run: $\mathrm{M}_{\mathrm{a}}$ : aboveground biomass (g) (base*3): $\alpha$ ': power-law allometric parameter (base*3); $\beta$ :

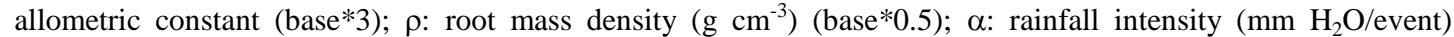
(base*5) d) Effects of soil's model parameters on the root density distribution function $\left(\mathrm{r}(\mathrm{z})=\mathrm{b}^{-1} \mathrm{e}^{-\mathrm{z} / \mathrm{b}}\right)$ : OM: organic matter (\%) (base*0.1); Silt : soil's silt content (\%) (base*10); Clay: soil’s clay content (\%) (base*10); n: soil porosity (base*0.25). 
3.4.1 Soil spatial interpolation

501 Spatial interpolation outcomes for the soil properties and plant biomass are shown in

502 Table 7. The predictive capacity of the implemented RF algorithms (Table 3) for the 503 soil texture $\left(\%\right.$ Sand: $\mathrm{R}^{2}=0.94$; $\%$ Fines: $\left.\mathrm{R}^{2}=0.93\right)$ and soil organic matter $\left(\mathrm{R}^{2}=0.88\right)$ was

504 high while it was relatively low for the plant biomass cover $\left(\mathrm{R}^{2}=0.31\right)$.

505 Table 7. Outcome from random forest (RF) spatial interpolations for each of the considered soil spatial variables. $506 \quad \mathrm{R}^{2}$ : coefficient of determination; RMSE: root-mean-square-error.

\begin{tabular}{lccl}
\hline \multicolumn{1}{c}{ Spatial variable } & $\begin{array}{c}\text { Variance } \\
\text { explained (\%) }\end{array}$ & $\mathrm{R}^{2}$ & \multicolumn{1}{c}{ RMSE } \\
\hline Soil sand content (\%) & 62.86 & 0.94 & 11.82 \\
Soil fines content (\%) & 66.8 & 0.93 & 54.32 \\
Soil silt content (\%) & 34.1 & 0.66 & 57.02 \\
Soil organic matter (\%) & 42.78 & 0.88 & 1.11 \\
Dry bulk density $\left(\mathrm{g} / \mathrm{m}^{3}\right)$ & 53.16 & 0.81 & 0.32 \\
Plant biomass $\left(\mathrm{g} / \mathrm{m}^{2}\right)$ & 33.59 & 0.31 & 841.51 \\
\hline
\end{tabular}

511 The outcome from the spatial prediction of the root spread is shown in Fig. 8 in terms

512 of the rooting depth (i.e. $z_{95}=3 b$; soil depth at which $95 \%$ of the roots can be found)

513 and in Fig. 9a in terms of the root profile distribution for 4 randomly chosen points

514 (i.e. Points A, B, C and D; Fig. 8). Results indicated a maximum herbs rooting depth

515 of ca. $200 \mathrm{~mm}$ on flat zones while steeper terrain presented shallower root depths (ca.

$516 \quad 100-125 \mathrm{~mm})$. 


\section{$95 \%$ Rooting Depth (mm)}

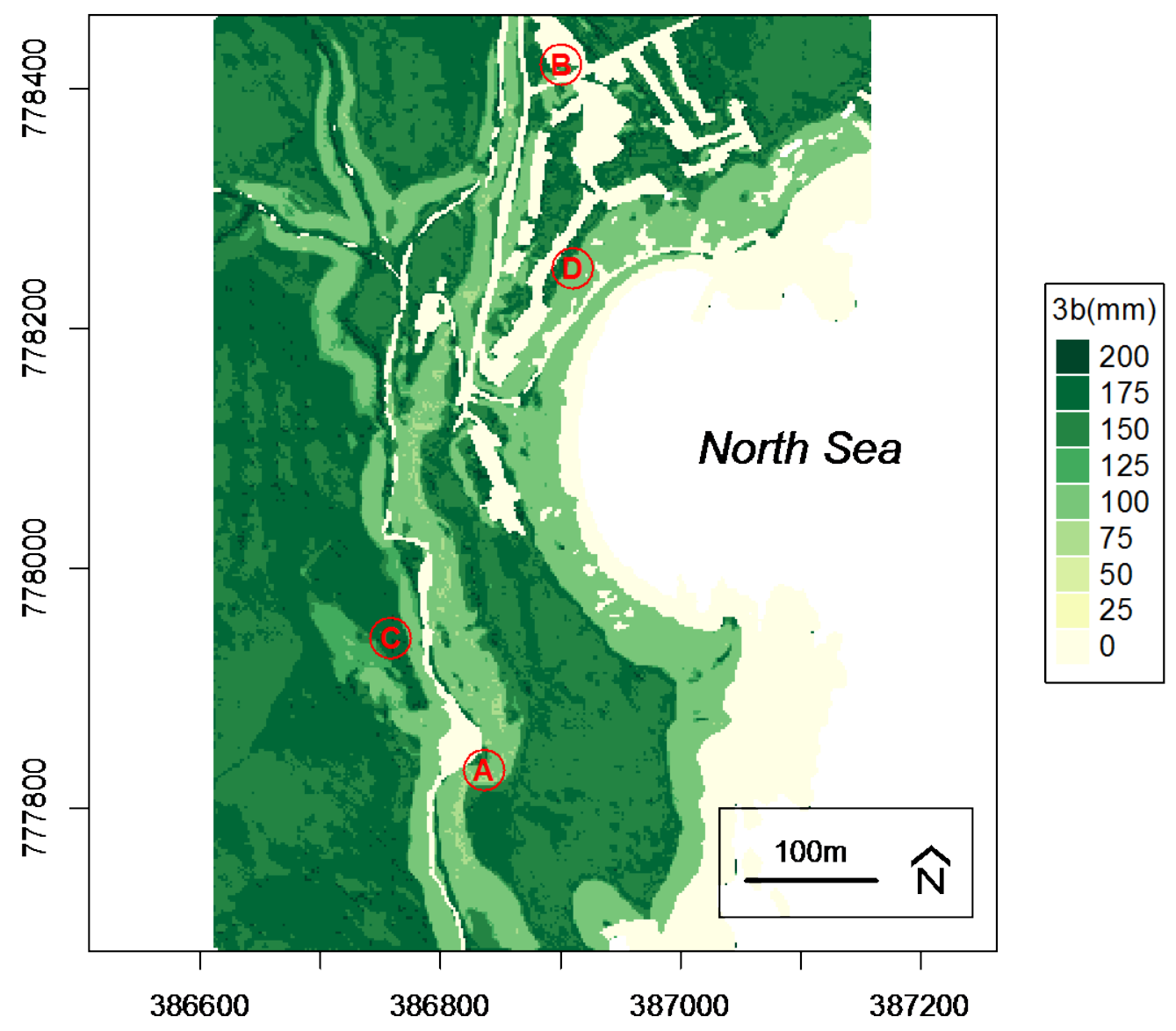

Figure 8. RPDM spatial predictions for the rooting depth $(\mathrm{mm})$ at which $95 \%$ of the root system can be found (i.e. $\mathrm{z}_{95}=3 \mathrm{~b}$ ) in the soil in our study site, and points A, B, C and D at which root reinforcement profiles were assessed.

3.5 Mechanical effect of root spread on slope stability

524 The mechanical effect of root spread on slope stability (Fig. 9b) for each randomly

525 selected point within the study area (i.e. Points A, B, C and D; Fig. 8) was limited to 526 the topmost soil (i.e. 0-200 mm) and showed differences in light of root spread 527 differences (Fig. 9a) provided by soil spatial properties differences. The predicted 528 apparent root cohesion (Fig. 9c) and its subsequent mechanical effect on slope 529 stability (Fig. 9d) for the 3 studied species and for the 2 additional treatments (i.e. oak tree and bare soil) pointed that it was Erigeron acris the most effective herb species 
531 from the soil-root reinforcement point. However, no statistically significant

532 differences were found between the 5 considered treatments $\left(\chi^{2}=7.82, \mathrm{df}=4\right)$.
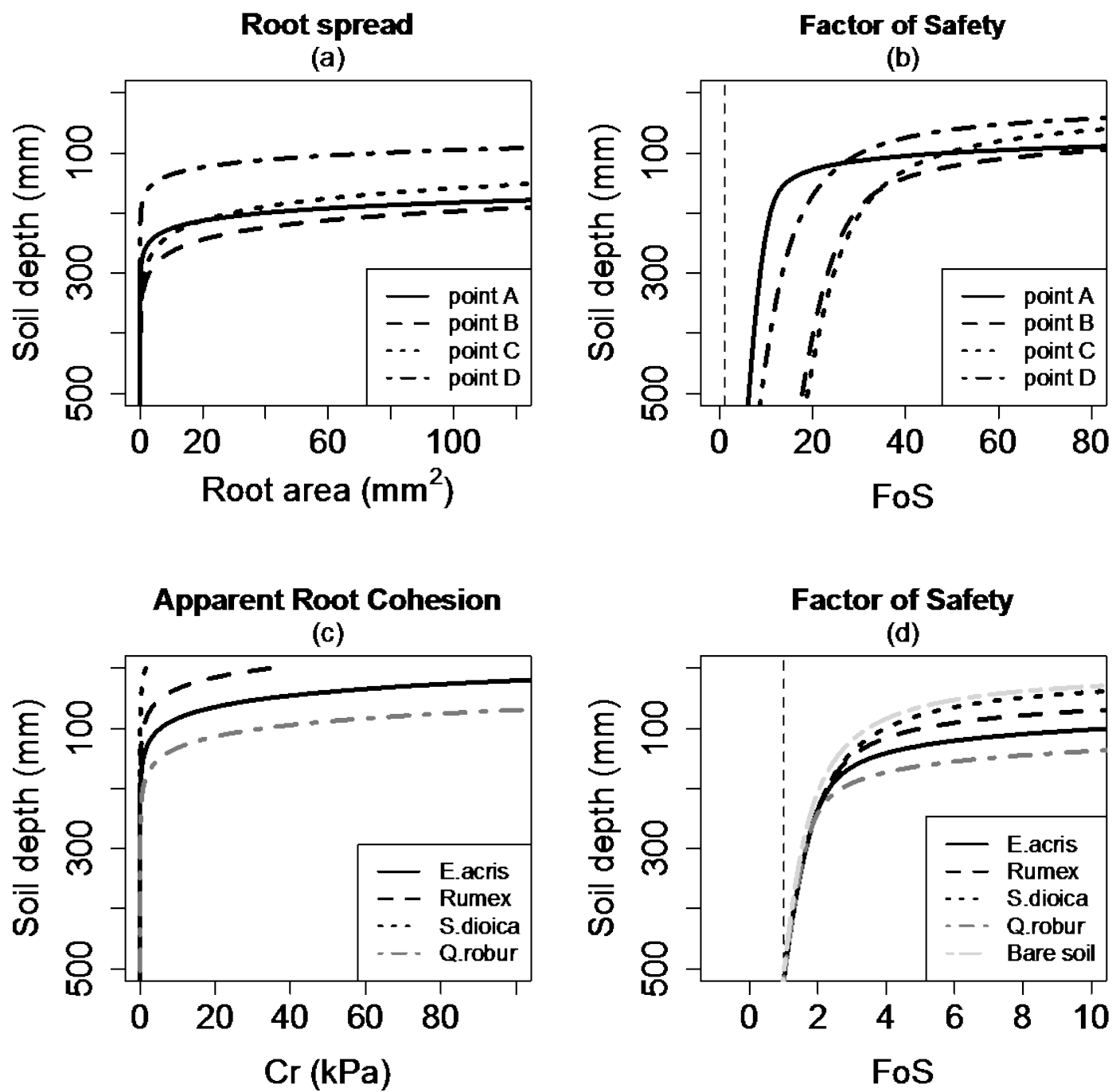

Figure 9. a) Predicted root spread in terms of the root cross-sectional area ( $A r)$ at four different points (i.e. pixels) within the study site and indicated in Fig. 7 b) Predicted Factor of Safety (FoS) profiles at the four points indicated in Fig. 7 c) Predicted apparent root cohesion profiles assuming fully-vegetated unit area of ground by each of the considered plant species d) Estimated Factor of Safety (FoS) profiles for each considered vegetation cover and bare soil, where FoS $<1$ = slope failure and Fos $>1$ = slope stable.

535 4. Discussion

539 All the stations presented a similar, and lower, ETP with respect to $R$ (Table 4),

540 representative of humid climates (UNEP, 1992), confirming that Laio's original 
541 model (Laio et al., 2006) is not applicable to our study area and supporting the need

542 of modification for our study site. In addition, the shape of the rainfall intensity

543 distribution function (Fig. 4a) was exponential for all the studied rainfall time series

544 belonging to our study site. Hence, according to Laio’s (2006) original model, the

545 root systems in our study region should be expected to be exponentially shaped;

546 supporting the assumption made in this regard (see 2.3.1).

547 In reference to the growing season duration (Table 4), only minor differences were

548 found between all the considered meteorological stations and with no summer

549 dormancy. The late start of the growing season in our study area compared to warmer

550 regions (e.g. Preti et al., 2010; Tron et al., 2014) would lead to a late start of the

551 vegetation activity that, for the case of annual herbs, would produce a negligible

552 effect on shallow soil instabilities until very late in the spring season. On the other

553 hand, rainfall events were evenly distributed over the entire year throughout the

554 considered time series (Fig. 4b). Consequently, the duration of the growing season

555 was not expected to have a significant impact on the RPDM predictions in this regard

556 (see 4.4). Nonetheless, in case of an uneven rainfall distribution throughout the year

557 (i.e. seasonal), an accurate determination of the growing season duration would be 558 paramount for a better prediction of the root distribution profiles (Tron et al., 2014).

559 Both the mean annual rainfall $(R)$, as well as the mean rainfall intensity during the

560 growing season $(\alpha)$ were considerably lower in our study site than for the rest of the 561 stations (Table 4) which presented wetter conditions. As a result of this, and based on 562 RPDM formulation (see 2.3), shallower root systems would be expected in our study 563 site in comparison with sites closer to the other meteorological stations. 
566 The results from the soil parameterisation (Table 5) suggest that rainfall infiltration

567 will not be constrained by the soil properties and the AWC to plants $\left(n\left(\theta_{f c}-\theta_{w p}\right)\right)$ will

568 be adequate for the development of root systems in depth. According to this, we

569 believe that rainfall infiltration will mainly be driven by gravity (i.e. producing a 570 vertical flow) despite the terrain steepness (Lu and Godt, 2013). Although runoff will 571 also be fostered by the topographical conditions once the topsoil moisture approaches 572 saturation levels (Mein and Larson, 1973), on average (i.e. throughout the growing 573 season) this will not affect significantly the water availability for root development 574 (Tron et al., 2014). Additionally, lateral flow will not likely be produced until 575 infiltrating water reaches the bedrock (Neitsch et al., 2011), which, presumably, is out 576 of the root system's influence as root systems tend to be relatively shallow in 577 temperate humid climates (Schenk and Jackson, 2002).

4.3 Root spread and plant parameters

\subsubsection{Root spread}

The obtained exponential root profiles (Figs. 6a-6c) validate the assumption of

584 considering an exponentially shaped root distribution profile and corroborate Laio’s

585 notion (Laio et al., 2006) that the rainfall intensity distribution function largely 586 determines the root system's shape in the soil profile. However, on an individual 587 basis, it was observed that some profiles better resembled a gamma shaped 588 distribution (unpublished data). Hence, local ecological factors other than rainfall 589 distribution and water availability may have an influence on the shape of the root 590 profile (e.g. Casper et al., 2003; Schenk, 2005). 
591 All root systems just explored the uppermost soil profile (i.e. 0-300 mm b.g.l) and in 592 depths depending on the plant biomass (Fig. 6a-c; Table 6). In the same line, it was 593 also observed that the proportion of rooted soil (i.e. $R A R$ ) varied with plant biomass 594 (Table 6, Figs. 6a-c); the higher the plant biomass the higher the root cross-sectional 595 area in the topmost soil horizons. The fact that higher biomass plants tend to spread 596 wider and deeper may be related to the plant's own stabilisation in the ground 597 (Chiatante et al., 2003) or related to resources use efficiency and competition issues 598 with other plant species (Schenk, 2005).

599 The values of root exploration depth were in good agreement with globally observed 600 values for cool-temperate meadows (Schenk and Jackson, 2002; Yang et al., 2009), 601 alpine herbs (Burylo et al., 2011), and for cool temperate ecosystems in general, 602 where the upper $200 \mathrm{~mm}$ of the soil profile contains, on average, the majority of all 603 roots (Schenk \& Jackson, 2002). For the case of Rumex obtusifolius, its root 604 distribution matched the observations gathered in Laan et al. (1989) for riparian 605 ecosystems in the Netherlands. Our results were more realistic than the reported in the 606 literature (Cannadell et al., 1996; Schenk and Jackson, 2005), where it was postulated 607 that root systems could explore as much as $2 \mathrm{~m}$ depth of the soil profile for climate 608 parameters matching our study site's which is not achieved even by woody plants in 609 the UK (e.g. Nicoll \& Amstrong, 1998; Crow, 2005). It is worth noting that shallow 610 root systems were expected to be found as, indicated earlier (see 2.3.1), plant water 611 availability will not be constrained in the topmost soil horizons in temperate humid 612 climates. Nonetheless, it must be borne in mind that the whole root systems were 613 excavated from their natural environment, and different records may be obtained with 614 onsite measurement methods, such as the profile wall method (Böhm, 1979). 615 Regarding the observed $R A R$ values, these were in all cases lower than the values 
616 indicated, for example, in Comino et al. (2010) for other herbaceous species at a

617 hypothetical shear plane of $100 \mathrm{~mm}$. This indicates that the approach employed herein

618 for measuring the root cross-sectional area did not lead to overestimation of its value.

\subsubsection{Plant parameters}

Given that plant biomass had a significant effect on the root spread, the plant

623 allometry or the relationship between above and belowground vegetative parts, was

624 expected to be the key parameter for readily providing information on the root spread

625 using less invasive sampling methods and to support decisions on plant selection for 626 slope stabilisation.

627 As stated earlier (see 3.1.3), the three studied plant species showed different 628 allometric relationships between their respective above and belowground vegetative 629 parts (Figs. 6d-f). For the case of Rumex obtusifolius and Silene dioica a complete 630 isometric relationship was found (Figs. 6e-f), as indicated by Niklas (2005) for the 631 case of non-woody plant species. On the contrary, for the case of Erigeron acris an 632 exponential relationship was found between the two vegetative parts (Fig 6d), which 633 is not commonly observed in herbaceous plant species (Cheng and Niklas, 2007). The 634 value of $\alpha$ ' we recorded for $E$. acris was $0.43(\mathrm{n}=11, \mathrm{SE}=0.103$; Table 6) which 635 compares to the value of $3 / 4$ in the original WBE model (West et al., 1997). This may 636 be due to errors in the measuring technique (Enquist et al., 1998), or due to the limited 637 sample size. On the other hand, although we did not log-transformed the considered 638 variables (i.e. $M_{a}$ and $M_{r}$ ), as it is normally the case in most biometrical studies (West 639 et al., 1997), a clear allometric relationship was directly found using the 640 untransformed variables and with an ordinary least squares regression (OLS); which 
641 may be valid for plant species with lower biomass. In any case, the fitting parameters

$642 \beta$ and $\alpha^{\prime}$ differed across the three studied plant species, giving support to the idea of

643 'non-universal' scaling allometric parameters (Li et al., 2005). Nevertheless, it is

644 worth noting that the WBE general model (West et al., 1997; Enquist et al., 1998)

645 states that the scaling parameters are predicted to change in very precise numerical

646 ways attending to ontogeny or differences in ecological settings. Therefore, further

647 research is recommended to clarify the sensitivity of $\beta$ and $\alpha$ ' to different ecological

648 factors (e.g. light, nutrients, water, topography) and shed light on the employability of

649 these plant parameters upon plant selection for eco-engineering purposes.

650

651 4.4 Root profile distribution model (RPDM)

652

653

4.4.1 Model predictions and quality

654

655 The predictive capacity of RPDM was shown to be very high in all cases (Figs. 6a-c

656 and Table 6) as both the root distribution profiles (Figs. 6a-c) and coefficients of 657 determination (Table 6) pointed out. It must be borne in mind, however, that a better 658 goodness of fit was obtained when data from the in situ meteorological station were 659 employed as inputs. This outcome, despite stressing the realistic behavior of RPDM, 660 also highlights the relevance of using relevant site-specific data for predicting root 661 distribution profiles accurately, given that a level of natural variability should be 662 expected even within one relatively small study site. In this sense, the RPDM root 663 profile predictions were larger when inputs from the other 6 meteorological stations 664 were considered (Figs. 6a-c), as the rainfall values (Table 4) and the chances for 665 deeper water infiltration in the soil were higher. Nonetheless, RPDM also envisaged 
666

667

668

669

670

671

672

673

674

675

676

677

678

679

680

681

682

683

684

685

686

687

688

689

690

that when root systems were deeper, as a consequence of wetter conditions, the rooted area in the uppermost soil horizons (i.e. 0-50 mm) would also be smaller compared to our study site's drier conditions. This observation, although maybe related to resource allocation issues (e.g. Schenk, 2005) captured by RPDM, was generated by the fact that the plant biomass was not allowed to change under this wetter conditions and, thus, it had to be distributed over a greater soil depth.

On the other hand, the root spread predictions for the plant species with the highest biomass (i.e. Rumex obtusifolius) showed deeper and denser root systems, as indicated before. The plant biomass determined the root system biomass (i.e. $M_{r}$; see 2.2.3) through the established plant-species-specific allometric relationship (see 4.3.2), in turn affecting the value of the scaling parameter $\left(A r_{o}\right.$; see 2.3.1) which determined the root distribution profile. Thus, it can be expected that RPDM will predict deeper and denser root systems for higher biomass and woody vegetation (e.g. Gonzalez-Ollauri and Mickovski, 2014; see 4.4.2), as it is the case in reality (Ekanayake and Phillips, 2002; Schenk and Jackson, 2002; Mickovski et al., 2008). Nonetheless, it must be borne in mind that while for Erigeron acris and Rumex obtusifolius the mean $M_{a}$ between all the sampled individuals was utilized as input, for Silene dioica a better output was obtained when using the sum of $M_{a}$ for all the studied individuals (RPDM C and D; Table 6). This outcome may be due to the limited sample size and further research is recommended to clarify what approach performs best for low biomass plant species.

With regard to the prediction of $A r_{o}$ and $b$ (Table 6), RPDM projected values for both parameters satisfactorily when the study site's meteorological inputs were employed.

However, it must be borne in mind that he predicted $b$ values were well below respect to the values reported in Preti et al. (2010) for bushy species in a Mediterranean 
691

setting. This outcome was expected given the climatic differences with our study site, where AWC to plants is expected to accumulate at the soil surface, hence, leading to shallower root systems in temperate humid climates as indicated in 4.3.1. Nontheless, RPDM presented two main limitations in relation to the parameters $A r_{o}$ and $b$. On the one hand, $A r_{o}$ is determined by the plant biomass and allometry. Since the latter seemed not to be 'universal' in spite of the 'global' relationships for different plant types and biomes reported in the literature (e.g. Cheng \& Niklas, 2007), costly species-specific information is needed to feed the model. On the other, $b$ is entirely dependent on the site's pedoclimatic conditions, meaning that the same mean rooting depth is predicted regardless of the vegetation type, family or species.

\subsubsection{Model sensitivity}

The sensitivity analysis showed that RDPM is relatively sensitive (i.e. PV>20\%) to plant features (i.e. biomass and allometry) and to rainfall intensity, and relatively insensitive (i.e. $\mathrm{PV}<20 \%$ ) to the soil properties (Figs. 7a-d). The parameters that presented a negative sensitivity index (SI) generated an opposite effect on the root spread when they were higher in value. Contrariwise, those parameters that presented a positive SI favored the development of bigger root systems when their value was higher.

The two most sensitive, $M_{a}$ and $\beta$, directly affect the proportion of root biomass $\left(M_{r}\right)$, the value of $A r_{o}$ for a given plant species, and the root system depth. A three fold increase of $\beta$, for instance, led to a drastic reduction of the root profile distribution (Fig. 7c), whereas a three fold increase in plant biomass led to a considerably deeper and wider root system profile (Fig. 7c). Again, these outcomes highlight how 
important is to have species-specific information to accurately predict the distribution

717 of the root profile which would be easily obtained for known plant allometric

718 parameters. Regarding the third most sensitive parameter, as it has been discussed

719 previously, an increase of $\alpha$ would enhance the chances of deeper water infiltration in

720 the soil profile, favoring the development of root systems that explore the soil profile

721 deeper as deeper water will be available. In addition, the root mass density $\left(\rho_{r}\right)$ was

722 relatively sensitive which highlighted the fact that plant-species specific values of $\rho_{r}$

723 easily estimated by the water volume displacement method (e.g. Hughes, 2005) could

724 lead to better root spread predictions.

725 The soil properties, even though shown to be insensitive, produced a subtle effect on

726 the root density distribution (i.e. $r(z)=b^{-1} e^{-z / b}$; Laio et al., 2006) that was captured by

727 RPDM (Fig. 7d) which may be related to the allocation and availability of resources

728 in the soil profile (Schenk, 2005). For example, a 10-fold decrease in organic matter

729 content led to a shallower and less extensive root system. On the contrary, a 3-fold

730 decrease in soil porosity led to a smaller but deeper root system that would be better

731 adapted to exploring and using resources deeper in the soil profile as observed in the

732 nature by the authors. As the plants can grow on nearly any substrate, and based on

733 our results, as well as the literature (e.g. Schenk and Jackson, 2002; Laio et al., 2006),

734 the plant root development would be mainly determined by the climate with the soil

735 properties affecting plant nourishment and wellbeing.

737 4.5 Spatially distributed RPDM

739 Spatially distributed RPDM successfully predicted a range of rooting depths (i.e. $740 z_{95}=3 b$ ) depending on the terrain features (Fig. 8). In this regard, RPDM predicted 
741 shallower rooting depths for steeper terrain (i.e. lighter areas in Fig. 8) opposed to flat 742 zones (i.e. darker areas in Fig. 8). The obtained outcome was consistent with the 743 observations indicated in Hales et al. (2009), stating that vertical root distributions 744 vary as a function of landscape position, likely encouraged by resources availability 745 (Schenk, 2005). In this sense, topographical gradients may make water and nutrients 746 less prone to accumulate along the slope gradient, being a plausible cause for 747 shallower root spread in steep terrain. Additionally, plastic adaptations to which 748 plants growing on slopes are subject to could also induce root spread alterations, such 749 as the upslope root spread for plant anchorage purposes (Chiatante et al., 2003), 750 which allegedly would prevent the root system from spreading downwards if the 751 allometry holds. Nonetheless, it is worth noting that the model outcome was 752 determined by the ability of RF to capture realistically the spatial heterogeneity of the 753 soil properties driving root spread. In this sense, soil spatial input variables for RPDM 754 (Table 3), obtained through implementing RF, showed a good fit with the 755 environmental covariates in terms of the explained variance (Table 7). These 756 outcomes therefore indicate that RF can be a powerful machine learning technique 757 when applied to the prediction of soil spatial attributes. However, for the case of plant 758 biomass, refinement of the employed covariates and inputs is needed to improve the 759 model's output, as its goodness of fit was not that satisfactory. Additonally, other 760 spatial covariates than the ones considered herein will have an influence on the spatial 761 distribution of plant biomass (e.g. soil nutrients, sunlight exposure, etc.). We also 762 believe that temporal data from more than just one growing season would enhance the 763 model's quality as well, since the relationship, if any, between plant biomass and the 764 other environmental covariates should be expected to be clearer with a larger dataset. 
768 When the root profiles from 4 random pixels were retrieved from within our study site

769 (Fig. 8; Points A, B, C and D), prediction differences in terms of root spread and soil770 root mechanical reinforcement were clearly observed (Figs. 9a-b). Vegetated flat 771 areas (e.g. Fig. 8, point B), for instance, presented considerably higher stability (Fig. 772 9b), as it could be expected. On sloping zones (i.e. Fig. 8, points A and D), however, a 773 denser plant cover (e.g. Fig. 8, point A) provided higher soil-root mechanical 774 reinforcement (Fig. 9a) and better stability conditions in depth (Fig. 9b). These 775 observations further verify the behavior of the spatially distributed RPDM.

776 In terms of the considered plant species under equal soil properties, the one with the 777 highest biomass (i.e. Quercus robur) presented the highest and deepest soil-root 778 mechanical reinforcement (Figs. 9c-d). Nonetheless, despite having assigned to the 779 former a $T_{r}$ that doubled the one assigned to the herbaceous species (i.e. $8 \mathrm{MPa}$ vs. $7803.73 \mathrm{MPa}$ ), its mechanical reinforcement was comparable to the one provided by the 781 lowest $M_{a}$ species (i.e. Erigeron acris). In fact, it was Erigeron acris, out of three 782 studied plant species, the one that showed the best performance from the soil 783 mechanical reinforcement point. This outcome has its origins in the values found for 784 the allometric fitting parameters (Table 6), which, as it has been stated, determine $A r_{o}$ 785 and ultimately scale the extent of the root spread. This issue led to Silene dioica to 786 present the lowest $M_{r}$ and hence, the lowest mechanical effect (Figs 9c-d). In addition, 787 it supports the potential significance of plant allometry respect to root mechanical 788 reinforcement (Hwang et al., 2015), which should be further investigated as potential 789 cost-effective proxy for plant species selection in eco-engineering interventions, as 790 indicated before. Contrariwise, it is worth stressing the performance of Rumex 
791 obtusifolius that, in turn, seemed to be also detected by its allometry. Despite having 792 the highest biomass, and the deepest root spread (Fig. 7, Table 6), its mechanical 793 reinforcement effect was considerably lower $\left(\chi^{2}=99, \mathrm{df}=61\right)$ than for Erigeron acris, 794 for which $M_{r}$ was 4 times smaller on an individual basis (Table 6). However, when a 795 fully-vegetated unit area of ground was considered, the belowground biomass for 796 Rumex was nearly 6 times lower than for E.acris (i.e. 701.79 g vs. 4127.72 g) due to 797 the found allometry and despite being the total aboveground biomass per unit area of 798 ground $\left(M_{a}{ }^{T}\right)$ more than 4 times higher for Rumex obtusifolius (Table 6). Indeed, 799 Rumex obtusifolius' root system is basically a taproot (Fig. 5) that, from the 800 mechanical point, would mainly provide anchorage to the plant. Upon soil-slope 801 failure this taproot would likely experiment a pullout mechanism (Mickovski et al., 802 2009) conferring less energy to the soil than root breakage (Waldron and Dakessian, 803 1981). Thus, its mechanical contribution to soil reinforcement should be assessed with 804 a pullout model (e.g. Ennos, 1990) instead of with a breakage model and a root-added 805 cohesion as it was the case here.

806 In any case, our model showed that all the considered plant species, besides Silene 807 dioica (i.e. lowest $M_{r}$ ), would contribute noticeably to slope stability (Fig. 9d) within 808 the topmost soil horizons. If predictions were confirmed, plant species like Erigeron 809 acris could prevent the loss of up to $0.4 \mathrm{~m}^{3}$ of soil per $\mathrm{m}^{2}$ of land considering that 810 there is a mechanical reinforcement of about $100 \mathrm{~mm}$ with respect to bare soil (Fig. 811 9d). However, no statistically significant differences were found between the 5 812 considered treatments $\left(\chi^{2}=7.82, \mathrm{df}=4\right)$. This outcome may be due to not considering 813 the hydrological effects of vegetation and assuming hydrostatic conditions in the soil 814 profile. Under hydrodynamic conditions marked differences between bare and 815 vegetated soil would be expected (Gonzalez-Ollauri and Mickovski, 2014). In this 
816 sense, soil suction triggered by plant water uptake would enhance the soil stability 817 conditions (e.g. Wilkinson et al., 2002). In addition, it is worth noting that all the FoS 818 profiles converged in 1 (i.e. limit equilibrium) at the lower boundary of the soil 819 profile (Fig. 9d). This is produced due to setting $500 \mathrm{~mm}$ as the lower boundary of our 820 system (i.e. critical plane) and due to assuming cohesionless conditions to stress plant 821 effects.

822

823

5. Conclusions

824

825 Based on our observations and findings, it can be concluded that:

826

827

- Pioneer herbaceous plant species present shallow root systems in temperate humid climates that can noticeably contribute to reduce soil loss and 830 landslides within the uppermost soil horizons.

833

834 - Plant biomass and allometry are key to determine the degree of soil-root reinforcement and, therefore, the eco-engineering potential of certain plant species.

837

- Our model successfully predicts root spread in temperate humid climates on a spatial basis, being its predictive capacity considerably improved when local input data are employed. 
- Machine-learning techniques, such as RF, present outstanding features to enhance the quality of spatial information and predictions.

- The hydrological effects of vegetation against landslides should be considered to have a better picture of the eco-engineering potential of given plant species. Furthermore, the relationship between plant allometry, climate and root-soil its final validation.

854 Acknowledgements

855 The authors thank the Catterline Brae Action Group (CBAG) for allowing us to carry 856 this research on their brae, kindly supplying meteorological data and providing needed logistical and friendly support.

\section{References}

Alvarez-Uria, P. and Körner, C., 2007. Low temperature kimits of root growth in decidious and evergreen temperate tree species. Functional Ecology , 21, 211-218.

863 Allen, R., Pereira, L., Raes, D. and Smith, M., 1998. Crop evapotranspiration guidelines for computing crop water requirements. FAO Irrigation and drainage paper No 56.

865 BGS, 1999. British Geological Survey Rock Classification Scheme Vol. 3: Classification of sediments and sedimentary rocks. Research Report No RR 99-03. BGS, Nottingham, UK. 
Bivand, R. S., Pebesma, E.J. and Gomez-Rubio, V., 2008. Applied Spatial Data Analysis with R. Springer, New York, US.

Böhm, W., 1979. Methods of studying root systems; Ecological Studies 33. Springer-Verlag, New York, US.

871 Breiman, L., 2001. Random Forests. Machine Learning , 45, 5-32.

BS 1377 Part 2, 1990. Methods of test for soils for civil engineering purposes. Classification tests. British Standards Institution. London, UK.

Budyko, M., 1974. Climate and Life. Elsevier, New York, US.

875 Burylo, M., Hudek, C. and Rey, F., 2011. Soil reinforcement by the roots of six dominant species on eroded mountainous marly slopes (Southern Alps, France). Catena , 84, 70-78.

877 Canadell, J., Jackson, R.B., Ehleringer, J.R., Mooney, H.A., Sala, O.E. and Schulze, E.D., 1996.

878 Maximum rooting depth of vegetation types at the global scale. Oecologia , 108, 583-595.

879 Casper, B., Schenk, H.J. and Jackson, R.B., 2003. Defining a plant's belowground zone of influence. Ecology , 84 (9), 2313-2321.

881 Cheng, D. and Niklas, K.J., 2007. Above- and below-ground biomass relationships across 1534 forested communities. Annals of Botany , 99, 95-102.

883 Chiatante, D., Sarnataro, S., Di Iorio, A. and Scippa, G.S., 2003. The influence of steep slopes on root system development. J. Plant Growth Regul. 21, 247-260.

885 Coelho, M.B., Villalobos, F.J. and Mateos, L., 2003. Modeling root growth and the soil-plantatmosphere continuum of cotton crops. Agricultrual Water Management, 60, 99-118.

887 Comino, E., Marengo, P. and Rolli, V., 2010. Root reinforcement effect of different grass species: A comparison between experimental and models results. Soil \& Tillage Research , 110, 60-68.

889 Cornelini, P., Federico, C., Pirrera, ., 2008. Arbusti autoctoni mediterranei per l'ingenieria naturalistica. Primo contributo alla morfometria degli apparati radicali. Azienda Regionale Foreste Demaniali Regione Siciliana-Collana, Sicilia n.40

Craig, R., 2004. Craig's Soil Mechanics 7th Edition. E \& FN Spon, London, UK.

893 Crow, P., 2005. The influence of soils and species on tree root depth. UK Forestry Commission , Edinburgh, UK.

895 Daniel, C., 1973. One-at-a-time-plans. Journal of the American Statistical Association , 68, 353-360.

Darwin, C., 1880. The power of movement in plants. John Murray, London, UK. 
Deguchi, A., Hattori, S. and Park, H., 2006. The influence of seasonal changes in canopy structure on interception loss: Application of the revised Gash model. Journal of Hydrology , 318, 80-102.

Doppler, T., Honti, M., Zihlmann, U., Weisskopf, P. and Stamm, C., 2014. Validating a spatially distributed model with soil morphology data. Hydrol. Earth Syst. Sci., 18, 3481-3498.

901 Efron, B., 1979. Bootstrap methods: Another look at the Jackknife. Ann. Statist. , 1, 1-26.

Ekanayake, J.C. and Phillips, C.J., 2002. Slope stability thresholds for vegetated hillslopes: a composite model. Canadian Geotechnical Journal , 39 (4), 849-862.

Ennos, A., 1990. The anchorage of leek seedlings: the effect of root length and soil strength. Annals of Botany , 65, 409-416.

Enquist, B.J., Brown, J.H. and West, G.B., 1998. Allometric scaling pf plant energetics and population density. Nature , 395, 163-165.

Félix, R., and Xanthoulis, D., 2005. Analyse de sensibilité du modèle mathématique "Erosion Productivity Impact Calculator” (EPIC) par l'approche One-Factor-At-A- Time (OAT) .

911 GetMapping, 2014. GetMapping 2m resolution Digital Surface Model (DSM) for Scotland and Wales. Earth Observation

Data

Centre.

Retrieved

from

\section{3 http://cataloque.ceda.uk/uuid/4b0ed418e30819e4448dc89a27dc8388}

914 Gonzalez-Ollauri, A. and Mickovski, S.B., 2014. Integrated model for the hydro-mechanical effects of 915 vegetation against shallow landslides. EQA , 13, 35-59.

916 Hughes, S., 2005. Archimedes revisited: a faster, better, cheaper method of accurately measuring the 917 volume of small objects. Physics Education , 40 (5), 468-474.

918 Hales, T.C., Ford, C.R., Hwang, T., Vose, J.M. and Band, L.E., 2009. Topographic and ecologic 919 controls on root reinforcement. Journal of Geophysical Research , 114 (F03013), 1-17.

920 Head, K. H., 1980. Manual of Soil Laboratory Testing. CRC Press, Boca Raton, US.

921 Head, K. H., and Epps, R. J., 2011. Manual of Soil Laboratory Testing: Permeability. Shear Strenght and Compressibility Tests (Vol. 2). CRC Press, Boca Raton, US.

923 Hijmans, R., 2014. Raster: Geographical data analysis and modeling. R package version 2.3-12 . URL: 

2015. Simulating vegetation controls on hurricane-induced shallow landslides with a distributed ecohydrological model. Journal of Geophysical Research: Biogeosciences.

928 IPCC, 2014: Climate Change 2014: Synthesis Report. Contribution of Working Groups I, II and III to

929 the Fifth Assessment Report of the Intergovernmental Panel on Climate Change [Core Writing Team,

930 R.K. Pachauri and L.A. Meyer (eds.)]. IPCC, Geneva, Switzerland.

931 Jackson, R.B., Canadell, J., Ehleringer, J.R., Mooney, H.A., Sala, O.E. and Schulze, E.D., 1996. A

932 global analysis of root distributions for terrestial biomes. Oecologia , 108, 389-411.

933 Jenny, H., 1941. Factors of soil formation: A system of quantitative pedology. McGraw-Hill, New 934 York, US.

Kincardineshire Observer, 2013/4/11. Retrieved on 7/7/2015 from http://www.kincardineshireobserver.co.uk/news/catterline-villagers-pull-together-to-clear-road-1$\underline{2890185}$

Köppen, W., 1884. The thermal zones of the Earth according to the duration of hot, moderate and cold periods and the impact of heat on the organic world. Meteorol. Z. , 1, 215-226.

Laan, P., Berrevoets, M.J., Lythe, S., Armstrong, W. and Blom, C.W.P.M., 1989. Root morphology

941 and aerenchyma formation as indicators of the flood-tolerance of rumex species. Journal of Ecology , 77, 693-703.

943 Laio, F., D'Odorico, P., and Ridolfi, L., 2006. An analystical model to relate the vertical root 944 distribution to climate and soil properties. Geophysical Research Letters , 33, L18401.

945 Li, H., Han, X. and Wu, J., 2005. Lack of evidence for 3/4 scaling of metabolism in terrestial plants. 946 Journal of Integrative Plant Biology , 47 (10), 1173-1183.

947 Liaw, A. and Wiener, M., 2002. Classification and regression by randomForest. R News , 2 (3), 18-22.

948 Liess, M., Glaser, B. and Huwe, B., 2012. Uncertainty in the spatial prediction of soil texture: 949 comparison of regression tree and random forest models. Geoderma, 170, 70-79.

$950 \mathrm{Lu}, \mathrm{N}$. and Godt, J., 2008. Infinite slope stability under steady unsaturated seepage conditions. Water 951 Resources Research, 44 (W11404).

952 Lu, N. and Godt, J., 2013. Hillslope Hydrology and Stability. Cambridge University Press, New York, 953 US. 
Malone, B., 2013. Use R for Digital Soil Mapping. Soil Security Laboratory, The University of Sidney, Australia.

956 McMaster, G.S. and Wilhelm, W.W., 1997. Growing degree-days: one equation, two interpretations. Agricultural and Forest Meteorology , 87, 291-300.

958 Mein, R.G. and Larson, C.L., 1973. Modeling infiltration during steady rain. Water Resources Research , 9 (2), 384-394.

960 Mickovski, S., Hallet, P., Bransby, M., Davis, M., Sonnenberg, R., and Bengough, A., 2009. Mechanical Reinforcement of Soil by Willow Roots: Impacts of Roots Properties and Root Failure Mechanisms. Soil Sci. Soc. Am. , 73 (4), 1276-1285.

Mickovski, S., Hallett, P., Bengough, A., Bransby, M., Davies, M., and Sonnenberg, R., 2008. The effect of willow roots on the shear strenght of soil. Advances in Geoecology , 39.

Neitsch, S., Arnold, J., Kiniry, J., and Williams, J., 2011. Soil and Water Assessment Tool; Theoretical Documentation. Water Resources Institute Technical Report No 406. Texas, US.

Nicoll, B. and Amstrong, A., 1998. Development of Prunus root systems in a citystreet: pavement damage and root architecture. The International Journal of Urban Forestry , 22 (3), 259-270.

Norris, J., Stokes, A., Mickovski, S., Cameraat, E., Van Beek, R., Nicoll, B., Achim, A., 2008. Slope Stability and Erosion Control: Ecotechnological Solutions. Springer, Doerdrecht, The Netherlands.

Nunes, L., Lopes, D., Castro, F. and Gower, S.T., 2013. Aboveground biomass and net primary production of pine, oak and mixed pine-oak forests on the Vila real district, Portugal. Forest

974 O’Brien E.E., Brown, J.S. and Moll. J.D., 2007. Roots in space: a spatially splicit model for belowground competition in plants. Proc. R. Soc. B., 274, 929-934.

976 Odum, E. P. and Barrett, G.W., 1971. Fundamentals of Ecology. Thomson, Philadelphia, US.

Parzen, E., 1962. On estimation of probability density function and mode. The Annals of Mathematical Statistics, 33, 1065-1076.

Perring, F.H. and Walters, S.M., 1982. Atlas of the British Flora. Botanical Society of the British Isles, Cambridge, UK.

Prasad, A.M., Iverson, L.R. and Liaw, A., 2006. Newer classification and regression tree techniques: bagging and random forest for ecological prediction. Ecosystems, 9, 181-199. 
Preti, F., Dani, A., and Laio, F., 2010. Root profile assessment by means of hydrological, pedological and aboveground vegetation information for bio-engineering purposes. Ecological Engineering , 36, 305-316.

Priestley, C., and Taylor, R., 1972. On the Assessment of Surface Heat Flux and Evaporation Using Large-Scale Parameters. Monthly Weather Review , 100 (2), 81-92.

R Development Core Team, 2014. R: A language and environment for statistical computing. Viena, Austria: R Foundation for Statistical Computing URL: http://www.R-project.org

Reynolds, W. D. and Elrick, D. E., 1990. Ponded Infiltration From a Single Ring: I, Analysis of Steady Flow. Soil Sci. Soc. Am. J. , 54, 1233-1241.

Savabi, M.R., Engman, E.T., Kustas, W.P., Rawls, W.J. and Kenemasu, E.T., 1989. Water balance and percolation. In L. a. Lane, USDA-Water Erosion Prediction Project: Hillslope Profile Model Documentation (Vol. Chapter 7). West Lafayette, US: USDA-ARS National Soil Erosion Research Laboratory.

Scharmer, K. and Greif, J., 2000. The European solar radiation atlas, Vol 2: Database and exploitation software. Les Presses de l'Ecole de Mines, Paris, France.

Schenk, H., 2005. Vertical vegetation structure below ground: scaling from root to globe. Progress in Botany , 66, 341-373.

Schenk, H.J. and Jackson, R.B., 2005. Mapping the global distribution of deep roots in relation to climate and soil characteristics. Geoderma , 126, 129-140.

Schenk, H., and Jackson, R., 2002. The global biogeography of roots. Ecological Monographs , 72 (3), 311-328.

1005 Magdoff, F. et al. Soil Organic Matter: Analysis and Interpretation (pp. 21-31). Soil Sci. Soc. Am., 1006 Madison, US.

1007 Stokes, A., Douglas, G., Fourcaud, T., Giadrossich, F., Gillies, C., Hubble, T., et al., 2014. Ecological mitigation of hillslope instability: ten key issues facing researchers and practitioners. Plant Soil , $377,1-23$.

1010

Stokes, A., Norris, J., van Beek, L., Bogaard, T., Cammeraat, E., Mickovski, S., et al., 2008. How 1011 vegetation reinforces soil on slopes. In J. Norris, A. Stokes, S. Mickovski, E. Cammeraat, R. van 

116). Springer, Dordrecht, The Netherlands.

1014 Tardio, G. and Mickovski, S. B., 2016. Implementation of eco-engineering design into existing slope

1015

1016

1017

1018

1019

1020

1021

1022

1023

1024

1025

1026

1027

1028

1029

1030

1031

1032

1033

1034

1035

1036

1037

1038

1039

1040 stability design practices. Ecological Engineering, 92: 138-147

Toth, B., Weynants, M., Nemes, A., Mako, A., Bilas, G. and Toth, G., 2015. New generation of hydraulic pedotransfer functions for Europe. European Journal of Soil Science , 66, 226-238.

Tsutsumi, D., Kosugi, K. and Mizuyama, T., 2003. Effect of Hydrotropism on Root System Development in Soybean (Glycine max): Growth Experiments and Model Simulation. J. Plant Growth Regul. , 21, 441-458.

Tron, S., Dani, A., Laio, F., Preti, F. and Ridolfi, L., 2014. Mean root depth estimation at landslide slopes. Ecological Engineering , 69, 118-125.

UK Met Office. MIDAS Land Surface Stations data, 1853-current. Retrieved from http://badc.nerc.ac.uk/view/badc.nerc.ac.uk_ATOM_dataent_ukmo-midas

UNEP (United Nations Environmental Programme),1992. World atlas of desertification . UNEP, London, UK.

Urbano, P., 1995. Tratado de fitotecnia general. Mundi-Prensa, Madrid, Spain.

USDA-NRCS, 1997. National grazing lands handbook. USDA-NRCS, Washington DC, US.

van Beek, R., Cammeraat, E., Andreu, V., Mickovski, S., \& Dorren, L., 2008. Hillslope processes: mass wasting, slope stability and erosion. In J. e. Norris, Slope stability and erosion control: Ecotechnological solutions (pp. 17-64). Springer, Dordrecht, The Netherlands.

vor de Poorte, P., 2011. Retrieved 7/24/2015 from PEDROX: live weather from Catterline: http://www.pedrox.com

Waldron, L.J. and Dakessian, S., 1981. Soil reinforcement by roots: calculation of increased soil shear resistance from root properties. Soil Science , 132 (6), 427-435.

Waldron, L. J., 1977. The Shear Resistance of Root-Permeated Homogeneous and Stratified Soil. Soil Sci. Soc. Am. J , 41 (5), 843-849.

West, G.B., Brown, J.H. and Enquist, B.J., 1997. A general model for the origin of allometric scaling laws in biology. Science , 276, 122-126. 
1041 Wilcox, R.R. and Keselman, H.J., 2003. Modern robust data analysis methods: Measures of central 1042 tendency. Psychological Methods , 8 (3), 254-274.

1043 Wilkinson, P.L., Anderson, M.G. and Lloyd, D.M., 2002. An integrated hydrological model for rain1044 induced landslide prediction. Earth Surface Processes and Landforms , 27, 1285-1297.

1045 Wu, H., McKinnell, W. and Swanston, D., 1979. Strength of tree roots and landslides on Prince of 1046 Wales Island, Alaska. Canadian Geotechnical Journal , 16 (1), 19-33.

1047 Wu, L., McGechan, M.B., Watson, C.A. and Baddeley, J.A., 2005. Developing existing plant root 1048 system architecture models to meet future agricultural challenges. Advances in Agronomy , 85, $1049 \quad 181-219$.

1050 Yang, Y., Fang, J., Ji, C. and Han, W., 2009. Above- and belowground biomass allocation in Tibetan 1051 grasslands. Journal of Vegetation Science , 20, 177-184

1052

1053 